medRxiv preprint doi: https://doi.org/10.1101/2021.01.06.21249322; this version posted January 6, 2021. The copyright holder for this preprint (which was not certified by peer review) is the author/funder, who has granted medRxiv a license to display the preprint in perpetuity.

It is made available under a CC-BY-NC-ND 4.0 International license.

\title{
Indirect impacts of the COVID-19 pandemic at two tertiary neonatal units in Zimbabwe and Malawi: an interrupted time series analysis
}

Simbarashe Chimhuya, MMED*1, Samuel R. Neal, MRes*2, Gwendoline Chimhini, MMED ${ }^{1}$, Hannah Gannon, MBChB ${ }^{2}$, Mario Cortina-Borja, $\mathrm{PhD}^{2}$, Caroline Crehan, $\mathrm{MSc}^{2}$, Deliwe Nkhoma, BSc ${ }^{3}$, Tarisai Chiyaka, $\mathrm{BSc}^{4}$, Emma Wilson, $\mathrm{PhD}^{2}$, Tim HullBailey, MPhil ${ }^{2}$, Felicity Fitzgerald, $\mathrm{PhD}^{5}$, Msandeni Chiume, MBBS $\ddagger^{6}$, and Michelle Heys, $M D($ Res $) \ddagger^{2}$

1. Child and Adolescent Health Unit, Faculty of Medicine and Health Sciences, University of Zimbabwe, Harare, Zimbabwe

2. Population, Policy and Practice Research and Teaching Department, UCL Great Ormond Street Institute of Child Health, University College London, UK

3. Parent and Child Health Initiative Trust, Lilongwe, Malawi

4. Biomedical Research and Training Institute, Harare, Zimbabwe

5. Infection, Immunity and Inflammation, UCL Great Ormond Street Institute of Child Health, University College London, UK

6. Department of Paediatrics, Kamuzu Central Hospital, Lilongwe, Malawi

${ }^{\star}$ Contributed equally as first author

†Corresponding author

¥ Contributed equally as last author

\section{Correspondence to:}

Dr Michelle Heys

Population, Policy and Practice Department,

UCL Great Ormond Street Institute of Child Health,

30 Guilford Street,

London, WC1N 1EH

Email: m.heys@ucl.ac.uk

Telephone: +44 (0)20 79052212

Word count: 2917

Keywords: COVID-19, neonatal, NICU, low-income countries, developing countries, global health 


\section{ABSTRACT}

Background: Deaths from COVID-19 have exceeded 1.8 million globally (January 2020). We examined trends in markers of neonatal care before and during the pandemic at two tertiary neonatal units in Zimbabwe and Malawi.

Methods: We analysed data collected prospectively via the NeoTree app at Sally Mugabe Central Hospital (SMCH), Zimbabwe, and Kamuzu Central Hospital (KCH), Malawi. Neonates admitted from 1 June 2019 to 25 September 2020 were included. We modelled the impact of the first cases of COVID-19 (Zimbabwe: 20 March 2020; Malawi: 3 April 2020) on number of admissions, gestational age and birth weight, source of admission referrals, prevalence of neonatal encephalopathy, and overall mortality.

Findings: The study included 3,450 neonates at $\mathrm{SMCH}$ and 3,350 neonates at $\mathrm{KCH}$. Admission numbers at SMCH did not initially change after the first case of COVID-19 but fell by $48 \%$ during a nurses' strike (Relative risk (RR) $0.52,95 \% \mathrm{Cl} 0 \cdot 40-0 \cdot 68, p<$ 0.002). At $\mathrm{KCH}$, admissions dropped by $42 \%$ (RR 0.58; $95 \% \mathrm{Cl} 0.48-0.70 ; p<0.001)$ soon after the first case of COVID-19. At $\mathrm{KCH}$, gestational age and birth weight decreased slightly ( 1 week, 300 grams), outside referrals dropped by $28 \%$, and there was a slight weekly increase in mortality. No changes in these outcomes were found at $\mathrm{SMCH}$.

Interpretation: The indirect impacts of COVID-19 are context-specific. While this study provides vital evidence to inform health providers and policy makers, national data are required to ascertain the true impacts of the pandemic on newborn health.

Funding: International Child Health Group, Wellcome Trust. 
medRxiv preprint doi: https://doi.org/10.1101/2021.01.06.21249322; this version posted January 6, 2021. The copyright holder for this preprint (which was not certified by peer review) is the author/funder, who has granted medRxiv a license to display the preprint in perpetuity.

It is made available under a CC-BY-NC-ND 4.0 International license .

\section{RESEARCH IN CONTEXT}

\section{Evidence before this study}

We searched PubMed for evidence of the indirect impact of the COVID-19 pandemic on neonatal care in low-income settings using the search terms neonat* or newborn, and COVID-19 or SARS-CoV 2 or coronavirus, and the Cochrane low and middle income country (LMIC) filters, with no language limits between 01.10.2019 and 21.11.20. While there has been a decrease in global neonatal mortality rates, the smaller improvements seen in low-income settings are threatened by the direct and indirect impact of the COVID-19 pandemic. A modelling study of this threat predicted between 250000-1.1 million extra neonatal deaths as a result of decreased service provision and access in LMICs. A webinar and survey of frontline maternal/newborn healthcare workers in $>60$ countries reported a decline in both service attendance and in quality of service across the ante-, peri- and post-natal journey. Reporting fear of attending services, and difficulty in access, and a decrease in service quality due to exacerbation of existing service weaknesses, confusion over guidelines and understaffing. Similar findings were reported in a survey of healthcare workers providing childhood and maternal vaccines in LMICs. One study to date has reported data from Nepal describing an increase in stillbirths and neonatal deaths, with institutional deliveries nearly halved during lockdown.

\section{Added value of this study}

To our knowledge, this is the first and only study in Sub-Saharan Africa describing the impact of COVID-19 pandemic on health service access and outcomes for newborns in two countries. We analysed data from the digital quality improvement and data collection tool, the NeoTree, to carry out an interrupted time series analysis of newborn admission rates, gestational age, birth weight, diagnosis of hypoxic ischaemic encephalopathy and mortality from two large hospitals in Malawi and Zimbabwe ( $n \sim 7000$ babies). We found that the indirect impacts of COVID-19 were context-specific. In Sally Mugabe Central Hospital, Zimbabwe, initial resilience was demonstrated in that there was no evidence of change in mortality, birth weight or gestational age. In comparison, at Kamuzu Central Hospital, Malawi, soon after the first case of COVID-19, the data revealed a fall in admissions (by $42 \%$ ), gestational 
age (1 week), birth weight (300 grams), and outside referrals (by $28 \%$ ), and there was a slight weekly increase in mortality (2\%). In the Zimbabwean hospital, admission numbers did not initially change after the first case of COVID-19 but fell by $48 \%$ during a nurses' strike, which in itself was in response to challenges exacerbated by the pandemic.

\section{Implications of all the available evidence}

Our data confirms the reports from frontline healthcare workers of a perceived decline in neonatal service access and provision in LMICs. Digital routine healthcare data capture enabled rapid profiling of indirect impacts of COVID-19 on newborn care and outcomes in two tertiary referral hospitals, Malawi and Zimbabwe. While a decrease in service access was seen in both countries, the impacts on care provided and outcome differed by national context. Health systems strengthening, for example digital data capture, may assist in planning context-specific mitigation efforts. 


\section{LIST OF ABBREVIATIONS}

\begin{tabular}{|l|l|}
\hline app & application \\
\hline $\mathrm{Cl}$ & confidence interval \\
\hline COVID-19 & coronavirus disease 2019 \\
\hline KCH & Kamuzu Central Hospital \\
\hline LMIC & low-income and middle-income country \\
\hline NE & neonatal encephalopathy \\
\hline NNU & neonatal unit \\
\hline RR & Relative risk \\
\hline SD & standard deviation \\
\hline SMCH & Sally Mugabe Central Hospital \\
\hline
\end{tabular}

\section{LIST OF FIGURES}

Figure 1: Trend in daily admissions to the neonatal unit (seven-day moving average) ........ 12

Figure 2: Interrupted time series for weekly admissions to the neonatal unit ................... 14

Figure 3: Interrupted time series for gestational age and birth weight ........................... 16

Figure 4: Interrupted time series for outside referrals to the neonatal unit ........................ 17

Figure 5: Interrupted time series for prevalence of neonatal encephalopathy .................... 18

Figure 6: Interrupted time series for overall mortality ............................................... 20

Figure 7: Possible factors influencing the decrease in admissions to the neonatal unit ....... 22 
medRxiv preprint doi: https://doi.org/10.1101/2021.01.06.21249322; this version posted January 6, 2021. The copyright holder for this preprint (which was not certified by peer review) is the author/funder, who has granted medRxiv a license to display the preprint in perpetuity.

It is made available under a CC-BY-NC-ND 4.0 International license .

\section{INTRODUCTION}

The World Health Organization declared coronavirus disease (COVID-19) a Public Health Emergency of International Concern on 30 January 2020. ${ }^{1}$ Confirmed cases have exceeded 80 million globally with nearly two million deaths. ${ }^{2}$ Zimbabwe recorded its first case on 20 March and has reported $>17000$ cases with $>400$ deaths to date. ${ }^{2}$ Malawi confirmed its first three cases on 3 April and has reported $\sim 7000$ cases and $\sim 200$ deaths to date. ${ }^{2}$

Before the COVID-19 pandemic, considerable improvements were made in global child health: the global neonatal mortality rate fell from 31 to 18 deaths per 1,000 live births between 2000 and $2018 .{ }^{3}$ Yet there were disparities in the rates of decline with the sub-Saharan Africa region facing highest neonatal mortality rates ${ }^{3}$. Now, there is a danger that health outcomes in low-income and middle-income countries (LMICs) will fall further behind high-income countries. While countries worldwide face challenges related to the COVID-19 pandemic, LMICs are particularly struggling with financial constraints, limited testing capacity, lack of personal protective equipment, and staff shortages. ${ }^{4,5}$ As children are at low-risk of infection or severe disease from COVID-19, ${ }^{6-10}$ any impacts on their health outcomes will likely be attributable to the indirect effects of the pandemic on health systems, as in previous disease outbreaks. $^{11,12}$ These include increased rates of parental unemployment, food and housing insecurity, and reduced access to routine care. ${ }^{13,14}$

The NeoTree application (app) is an Android tablet-based quality improvement platform that aims to reduce neonatal mortality in LMICs. ${ }^{15}$ Developed in collaboration with local stakeholders, it is embedded in routine practice at two 
neonatal units (NNUs) in Zimbabwe and Malawi, providing real-time clinical decision support, neonatal care education, and digital data capture. ${ }^{16,17}$

We aimed to examine trends in markers of neonatal care before and during the COVID-19 pandemic at Sally Mugabe Central Hospital (SMCH), Zimbabwe, and Kamuzu Central Hospital (KCH), Malawi. Specifically, we compared the:

1. number of admissions,

2. gestational age and birth weight of admitted neonates,

3. source of admission referrals,

4. prevalence of neonatal encephalopathy (NE), and

5. overall mortality rate

before and after the first reported cases of COVID-19. 
medRxiv preprint doi: https://doi.org/10.1101/2021.01.06.21249322; this version posted January 6, 2021. The copyright holder for this preprint (which was not certified by peer review) is the author/funder, who has granted medRxiv a license to display the preprint in perpetuity.

It is made available under a CC-BY-NC-ND 4.0 International license .

\section{METHODS}

This study is reported in accordance with the Strengthening the Reporting of Observational Studies in Epidemiology (STROBE) statement (Appendix 1).

\section{Setting}

$\mathrm{SMCH}$ is a public referral hospital in Harare, Zimbabwe. It has the largest of three tertiary NNUs nationwide with 100 cots and predominantly doctor-led care. $\mathrm{KCH}$, Lilongwe, is one of four regional referral hospitals in Malawi and the NNU has 75 cots. In contrast to $\mathrm{SMCH}$, care in the NNU is mostly nurse-led. Both units accept local and national referrals for specialist surgical care.

\section{Participants}

All neonates admitted to each NNU over a 16-month period from 1 June 2019 to 25 September 2020 (69 complete weeks) were eligible for inclusion. We applied no specific exclusion criteria.

\section{Data collection}

Data were collected prospectively using the NeoTree app. Health workers complete a digital form when a neonate is admitted to the unit (admission form) and when they are discharged or die (outcome form). The app guides assessment of the neonate and collects data on patient demographics, examination findings, diagnoses, and interventions. Pseudonymised forms are uploaded monthly to University College London servers (Zimbabwe data) and Amazon Web Services (Malawi data). Admission and outcome forms are linked by a unique identifier generated by the app at admission. 


\section{Outcomes}

We evaluated five outcomes:

1. Number of admissions: determined from the admission date of each completed admission form.

2. Gestational age at birth (weeks) and birth weight (grams): as entered into the admission form from obstetric records.

3. Source of admission: defined as 'within' (labour ward, postnatal ward, antenatal ward, obstetric theatre, or fee-paying ward [ $\mathrm{KCH}$ only]) or 'outside' (referral from another health facility or postnatal self-referral from home).

4. Diagnosis of NE: defined as "hypoxic ischaemic encephalopathy" or "birth asphyxia" recorded as a diagnosis, cause of death or contributory cause of death on the outcome form.

5. Mortality: defined as an outcome of "neonatal death" on the outcome form. All other neonates, including those discharged, transferred to another facility or who left on parental request, were considered alive.

\section{Ethical approval}

Research ethics approval was granted by the UCL Research Ethics Committee (17123/001) and ethics committees in Malawi (P.01/20/2909) and Zimbabwe (MRCZ/A/2570) (Appendix 2). The need to obtain informed consent was waived as we collected only pseudonymised data routinely documented for clinical care. 
medRxiv preprint doi: https://doi.org/10.1101/2021.01.06.21249322; this version posted January 6, 2021. The copyright holder for this preprint (which was not certified by peer review) is the author/funder, who has granted medRxiv a license to display the preprint in perpetuity.

It is made available under a CC-BY-NC-ND 4.0 International license .

\section{Statistical analysis}

Analyses were performed in $\mathrm{R}$ version $3.6 .3,{ }^{18}$ running on RStudio version 1.2.5033. ${ }^{19}$ First, admission forms were matched with their corresponding outcome form based on the unique identifier generated at admission. Lack of completed outcome forms (SMCH: $n=316[9.1 \%]$ KCH: $n=243[7.2 \%]$ ) or errors in entry of the unique identifier at discharge (SMCH: $n=318[9.2 \%]$ KCH: $n=182[5.4 \%])$ meant we were unable to match some admission forms with outcome forms (SMCH: $n=634[18.3 \%] ; \mathrm{KCH}: n=425[12.6 \%])$. For outcomes $1-3$, we based analyses on data from all admission forms, regardless of match status. For outcomes 4 and 5, we based analyses on matched records only. Matched records implying a negative admission duration (i.e. outcome date prior to admission date) were excluded (SMCH: $n=58[2 \%]$; $\mathrm{KCH}: n=25[1 \%]$ ). See Appendix 3 for a flow diagram of record inclusion. Missing data were excluded using pairwise deletion for each analysis as frequencies of missing values were minimal (Appendix 4).

This study used an interrupted time series design with weekly data windows. We considered the first confirmed case of COVID-19 in each country as the intervention (Zimbabwe: 20 March 2020; Malawi: 3 April 2020). ${ }^{2}$ For all outcomes, we hypothesised a level change impact model without a lag (for a description of these models, see Bernal et al. $\left.^{20}\right)$. Gestational age and birth weight were modelled with linear regression. All other outcomes were modelled using quasi-Poisson regression to account for overdispersion, ${ }^{21}$ with the logarithm of the number of admissions in each weekly window included as an offset. All SMCH models were adjusted for a period of doctors' strikes from 3 September 2019 to 22 January $2020 .{ }^{22} \mathrm{KCH}$ models were unadjusted. Additional models were constructed to explore the effects of a 
medRxiv preprint doi: https://doi.org/10.1101/2021.01.06.21249322; this version posted January 6, 2021. The copyright holder for this preprint (which was not certified by peer review) is the author/funder, who has granted medRxiv a license to display the preprint in perpetuity. It is made available under a CC-BY-NC-ND 4.0 International license.

nurses' strike in Zimbabwe (17 June to 9 September 2020) ${ }^{23}$ and alternative impact models. Nested models were compared with the F-test. See Appendix 5 for model details.

\section{Role of the funding source}

The funders had no role in study design, data collection, data analysis, data interpretation, or preparation of this manuscript. 


\section{RESULTS}

\section{Outcome 1: Admissions to the neonatal unit}

We included 3,450 neonates at $\mathrm{SMCH}$ and 3,350 neonates at $\mathrm{KCH}$. Figure 1 shows the seven-day moving average of admissions to the NNU.

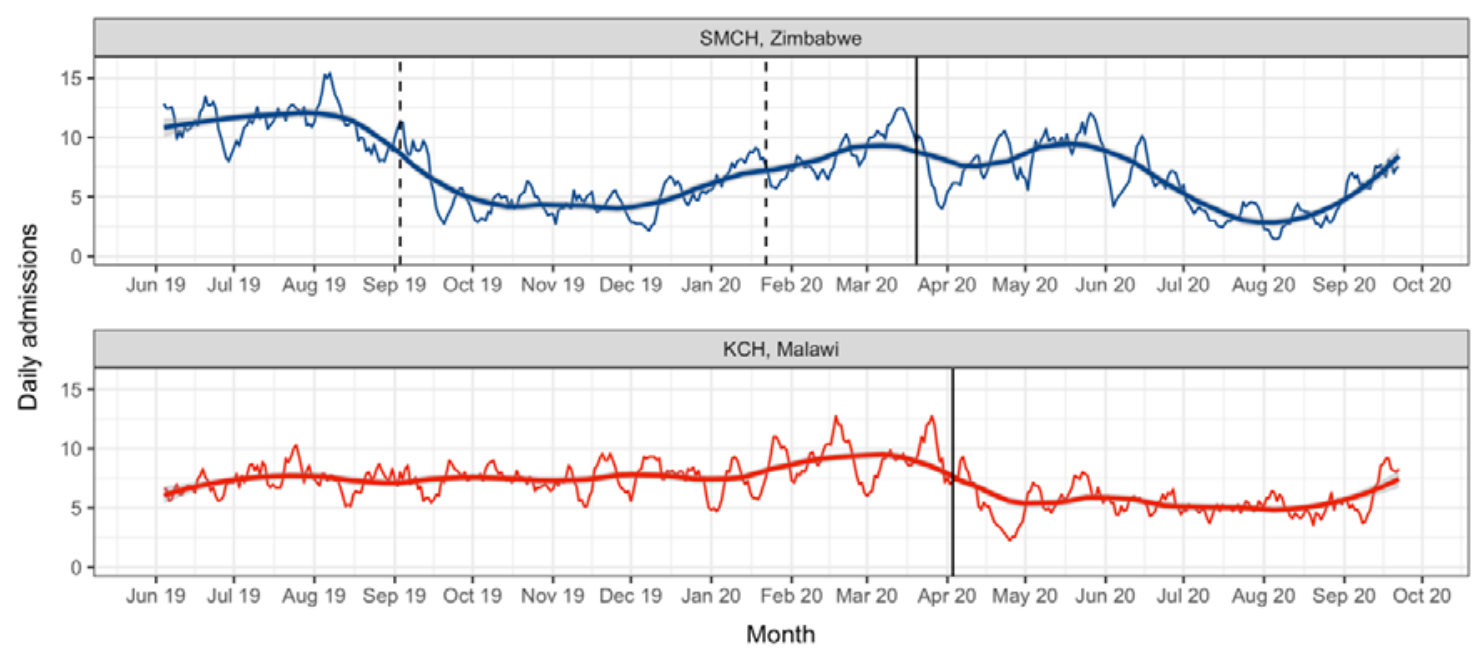

Figure 1: Trend in daily admissions to the neonatal unit

- The seven-day moving average of daily admission numbers has been plotted.

- Smoothed line: local regression (LOESS) model fitted on the seven-day moving average of daily admission numbers; shaded region: 95\% confidence interval.

- Solid vertical line: first confirmed case of COVID-19 in each country.

- Period between dashed vertical lines: industrial action by doctors in Zimbabwe.

- Counts based on all admission forms completed, irrespective of match status.

- SMCH: Sally Mugabe Central Hospital; KCH: Kamuzu Central Hospital

At $\mathrm{SMCH}$, the mean (SD) number of weekly admissions was $54.6(23.5)$ before the first case of COVID-19 (pre-COVID-19) and 42.8 (19.9) afterwards (post-COVID-19). The level change regression model, adjusted for the doctors' strike, showed no evidence of a change in admissions after the first case of COVID-19 (relative risk [RR] 0.83; 95\% confidence interval $[\mathrm{Cl}] 0.60-1.14 ; p=0.25)$ but the scatterplot indicated this model fit the data poorly (model 1, Figure 2A). An alternative model, 
additionally adjusted for the nurses' strike, again showed no change in the overall post-COVID-19 period (RR 0.90; 95\%Cl 0.69-1.17; $p=0.43$ ) (model 2, Figure 2B). However, this model suggested that admissions fell by $48 \%$ during the nurses' strike period $(\mathrm{RR} 0.52,95 \% \mathrm{Cl} 0.40-0.68, p<0.001)$ and fit the data better $(F 1,64]=$ 24.66, $p<0.001)$.

At $\mathrm{KCH}$, the mean (SD) number of weekly admissions was $54.5(10.8)$ in the preCOVID-19 period and $38.0(10.9)$ in the post-COVID-19 period. The level change model suggested a $42 \%$ reduction in admissions after the first case of COVID-19 (RR 0.58; 95\%Cl 0.48-0.70; $p<0.001$ ) (Figure 2C). 
A

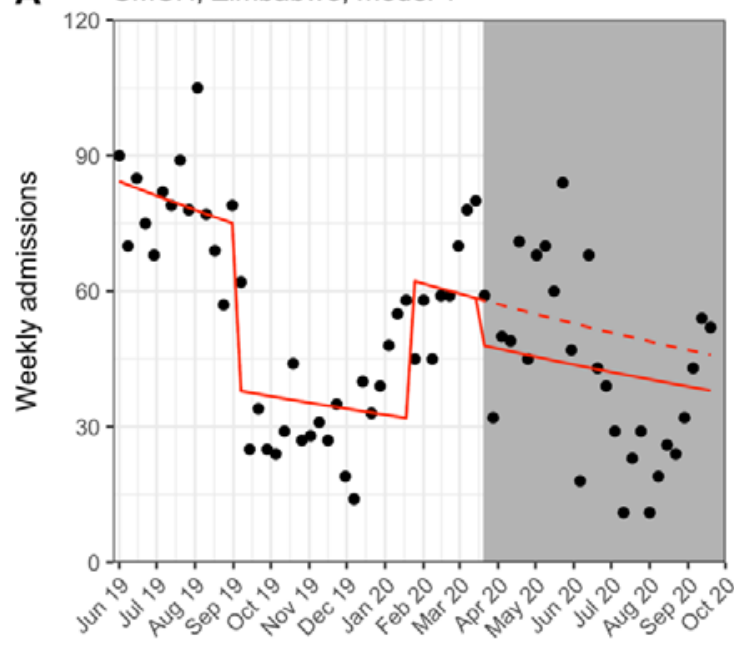

Month

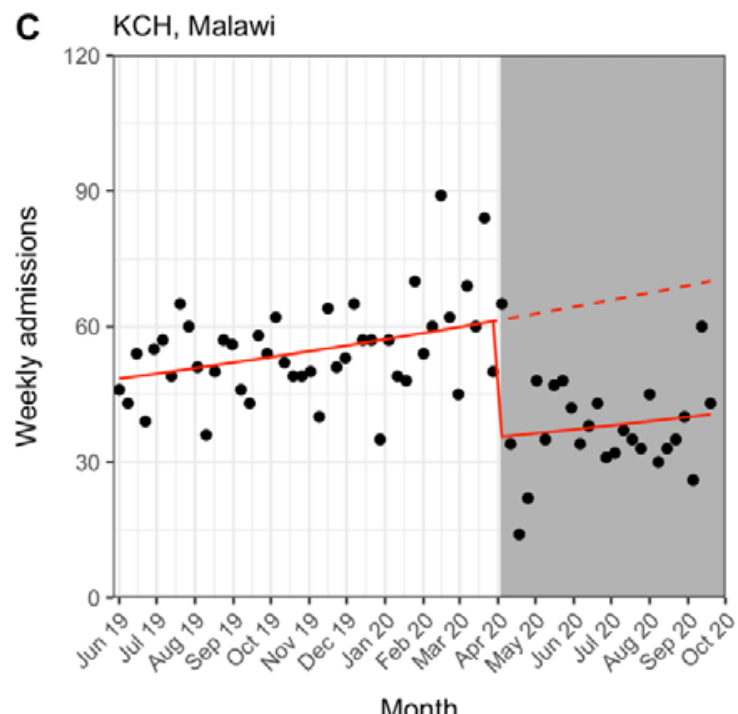

B $\mathrm{SMCH}$, Zimbabwe, model 2

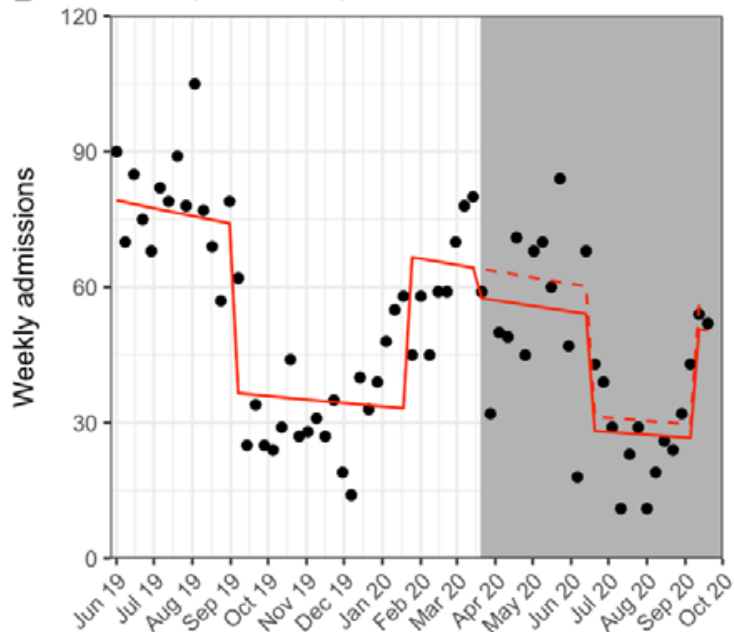

Month

Figure 2: Interrupted time series for weekly admissions to the neonatal unit

- White background: pre-COVID-19 period; grey background: post-COVID-19 period.

- Solid line: predicted trend from regression model; dashed line: counterfactual scenario.

- $\quad \mathrm{SMCH}$ model 1 (panel A) adjusted for doctors' strike period; SMCH model 2 (panel B) additionally adjusted for nurses' strike period; $\mathrm{KCH}$ model (panel C) unadjusted.

- Counts based on all admission forms completed, irrespective of match status.

- SMCH: Sally Mugabe Central Hospital; KCH: Kamuzu Central Hospital 
medRxiv preprint doi: https://doi.org/10.1101/2021.01.06.21249322; this version posted January 6, 2021. The copyright holder for this preprint (which was not certified by peer review) is the author/funder, who has granted medRxiv a license to display the preprint in perpetuity.

It is made available under a CC-BY-NC-ND 4.0 International license .

\section{Outcome 2: Gestational age and birth weight}

At $\mathrm{SMCH}$, the mean (SD) gestational age at birth was $36 \cdot 1$ (4.4) weeks in the preCOVID-19 period and $36 \cdot 0$ (4.2) weeks in the post-COVID-19 period. The mean (SD) birth weight was 2500 (908) grams in the pre-COVID-19 period and 2487 (896) grams in the post-COVID-19 period. Regression analysis indicated no change in gestational age at birth nor birth weight after the first case of COVID-19 (gestational age: beta $0.04 ; 95 \% \mathrm{Cl}-0.53-0.61 ; p=0.89$, birth weight: beta $-7 \cdot 2 ; 95 \% \mathrm{Cl}-127 \cdot 1$ 112.6; $p=0.91$ ) (Figure 3A, Figure 3C). Adjusting for the nurses' strike did not improve model fit (data not shown).

At $\mathrm{KCH}$, the mean (SD) gestational age was 35.0 (3.9) weeks in the pre-COVID-19 period and 34.8 (3.9) weeks in the post-COVID-19 period. The mean (SD) birth weight was 2402 (883) grams in the pre-COVID-19 period and 2299 (870) grams in the post-COVID-19 period. Gestational age decreased by one week in the postCOVID-19 period (beta -1.14; 95\%Cl -1.62-[-]0.65; $p<0.001$ ) (Figure 3B) and birth weight decreased by 300 grams (beta $-299.9 ; 95 \% \mathrm{Cl}-412 \cdot 3-[-] 187.5 ; p<0.001$ ) (Figure 3D). 
A

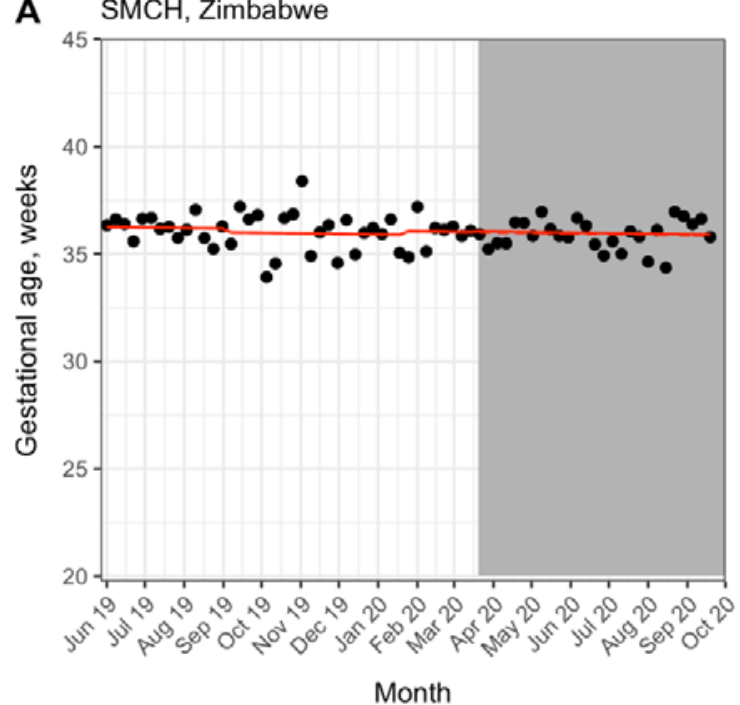

C
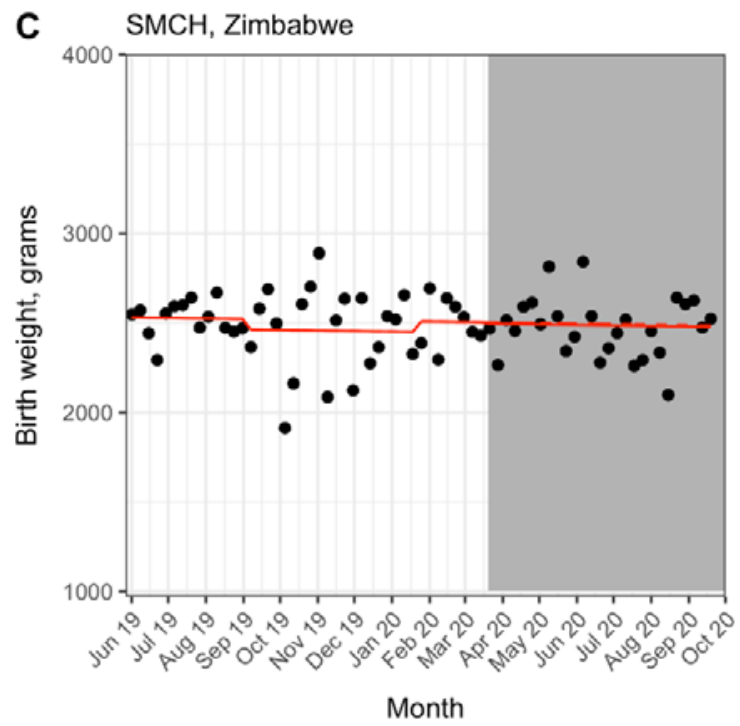

B $\mathrm{KCH}$, Malawi

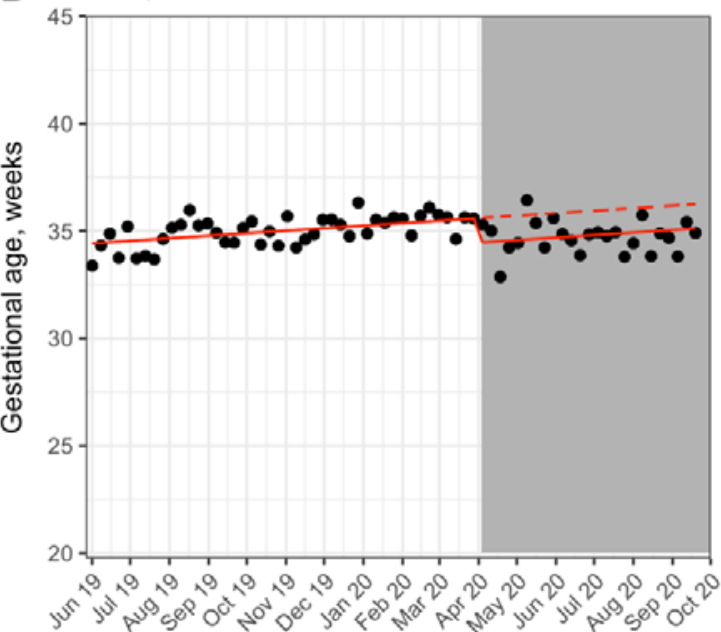

Month

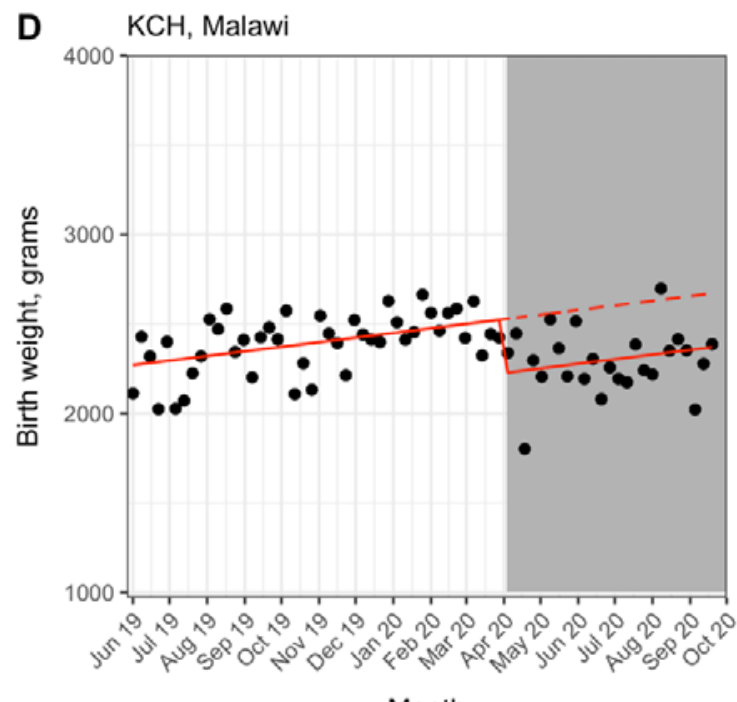

Figure 3: Interrupted time series for gestational age and birth weight

- Data points represent weekly mean gestational age or birth weight to avoid overplotting.

- White background: pre-COVID-19 period; grey background: post-COVID-19 period.

- Solid line: predicted trend from regression model; dashed line: counterfactual scenario.

- $\quad$ SMCH models (panels A \& C) adjusted for doctors' strike period, $\mathrm{KCH}$ models (panels $B$ \& $D$ ) unadjusted.

- Data from all admission forms completed, irrespective of match status.

- SMCH: Sally Mugabe Central Hospital; KCH: Kamuzu Central Hospital 
medRxiv preprint doi: https://doi.org/10.1101/2021.01.06.21249322; this version posted January 6, 2021. The copyright holder for this preprint (which was not certified by peer review) is the author/funder, who has granted medRxiv a license to display the preprint in perpetuity.

It is made available under a CC-BY-NC-ND 4.0 International license .

\section{Outcome 3: Source of admission referral}

At $\mathrm{SMCH}$, the mean (SD) percentage of outside referrals to the NNU was $39(11) \%$ in the pre-COVID-19 period and 35(9)\% in the post-COVID-19 period. The regression model showed no evidence of a change in the percentage of outside referrals after the first case of COVID-19 (RR $0.98 ; 95 \% \mathrm{Cl} 0.79-1.23 ; p=0.88$ ) (Figure 4A). Adjusting for the nurses' strike did not improve model fit (data not shown).

At $\mathrm{KCH}$, the mean (SD) percentage of outside referrals was $61(8) \%$ in the preCOVID-19 period and $51(10) \%$ in the post-COVID-19 period. Regression analysis suggested a $28 \%$ relative reduction in outside referrals after the first case of COVID19 (RR 0.72; 95\% Cl 0.65-0.81; $p<0.001$ ) (Figure 4B).

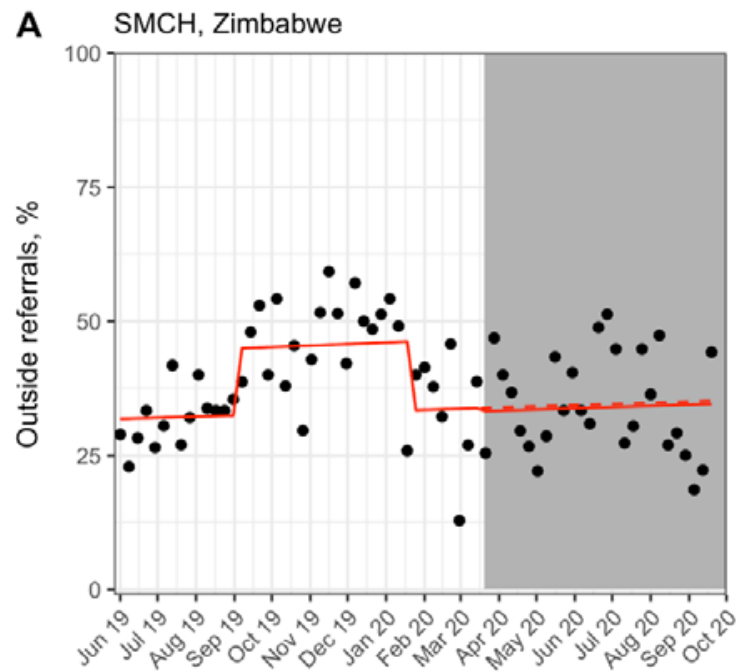

Month

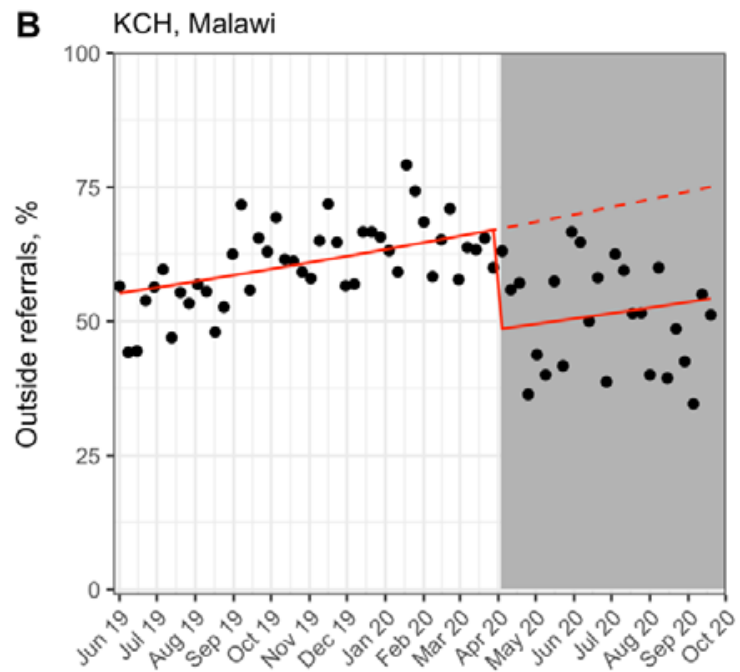

Month

Figure 4: Interrupted time series for outside referrals to the neonatal unit

- White background: pre-COVID-19 period; grey background: post-COVID-19 period.

- Solid line: predicted trend from regression model; dashed line: counterfactual scenario.

- $\mathrm{SMCH}$ model (panel A) adjusted for doctors' strike period, $\mathrm{KCH}$ model (panel B) unadjusted.

- Data from all admission forms completed, irrespective of match status.

- SMCH: Sally Mugabe Central Hospital; KCH: Kamuzu Central Hospital 
medRxiv preprint doi: https://doi.org/10.1101/2021.01.06.21249322; this version posted January 6, 2021. The copyright holder for this preprint (which was not certified by peer review) is the author/funder, who has granted medRxiv a license to display the preprint in perpetuity.

It is made available under a CC-BY-NC-ND 4.0 International license .

\section{Outcome 4: Prevalence of neonatal encephalopathy}

At $\mathrm{SMCH}$, the mean (SD) percentage of admitted neonates diagnosed with NE was $16(6) \%$ in the pre-COVID-19 period and $21(12) \%$ in the post-COVID-19 period suggesting a possible increase. Regression analysis showed no statistically significant change in the percentage of neonates diagnosed with NE post-COVID-19 (RR $1.08 ; 95 \% \mathrm{Cl} 0.76-1.55 ; p=0.67$ ) (Figure $5 \mathrm{~A}$ ). Adjusting for the nurses' strike did not improve model fit (data not shown).

At $\mathrm{KCH}$, the mean $(\mathrm{SD})$ percentage of admitted neonates diagnosed with NE was $15(6) \%$ in the pre-COVID-19 period and $13(5) \%$ in the post-COVID-19 period. The regression model suggested a possible increase in diagnoses of NE after the first case of COVID-19, but this was not statistically significant (RR 1.30; $95 \% \mathrm{Cl} 0.95$ $1 \cdot 80 ; p=0 \cdot 11)$ (Figure 5B).
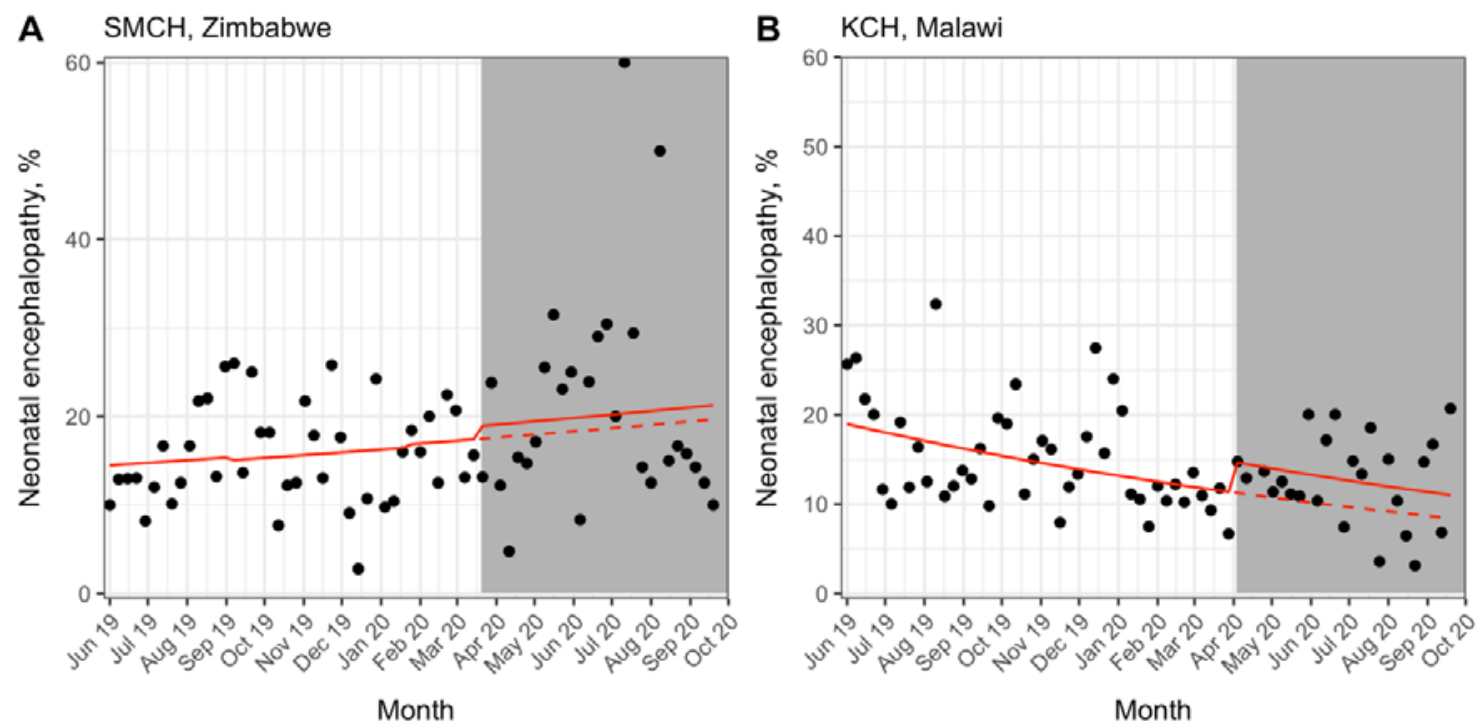

Figure 5: Interrupted time series for prevalence of neonatal encephalopathy

- White background: pre-COVID-19 period; grey background: post-COVID-19 period.

- Solid line: predicted trend from regression model; dashed line: counterfactual scenario.

- $\mathrm{SMCH}$ model (panel A) adjusted for doctors' strike period, $\mathrm{KCH}$ model (panel B) unadjusted. 
medRxiv preprint doi: https://doi.org/10.1101/2021.01.06.21249322; this version posted January 6, 2021. The copyright holder for this preprint (which was not certified by peer review) is the author/funder, who has granted medRxiv a license to display the preprint in perpetuity.

It is made available under a CC-BY-NC-ND 4.0 International license.

- Data from matched admission and outcome forms only.

- SMCH: Sally Mugabe Central Hospital; KCH: Kamuzu Central Hospital

\section{Outcome 5: Overall mortality}

For $\mathrm{SMCH}$, the mean (SD) percentage of deaths per week of admission was $25(10) \%$ in the pre-COVID-19 period and $26(16) \%$ in the post-COVID-19 period. The level change regression model, adjusted for the doctors' strike, showed no evidence of a change in mortality after the first case of COVID-19 (RR 0.80; 95\% Cl 0.56-1.15; $p=0.23$ ) but the scatterplot indicated this model fit the data poorly (model 1, Figure 6A). An alternative model, additionally adjusted for the nurses' strike, again showed no change in overall mortality ( $\mathrm{RR} 0.72 ; 95 \% \mathrm{Cl} 0.51-1.03 ; p=0.07$ ) but fit the data better $(F[1,64]=11 \cdot 61, p=0.001)($ model 2, Figure $6 B)$.

For $\mathrm{KCH}$, the mean (SD) percentage of deaths per week of admission was $19(6) \%$ in the pre-COVID-19 period and 23(9)\% in the post-COVID-19 period. The level change regression model suggested a possible increase in mortality after the first case of COVID-19, but this was not statistically significant (RR $1.31 ; 95 \% \mathrm{Cl} 0.98-$ 1.73; $p=0.07$ ) (Figure 6C). However, fitting a slope change impact model suggested a small relative increase in mortality by $2 \%$ per week in the post-COVID-19 period (RR 1.02 per week; 95\%Cl 1.00-1.04, $p=0.04$ ) (Figure 6D). 
medRxiv preprint doi: https://doi.org/10.1101/2021.01.06.21249322; this version posted January 6, 2021. The copyright holder for this preprint (which was not certified by peer review) is the author/funder, who has granted medRxiv a license to display the preprint in perpetuity.

It is made available under a CC-BY-NC-ND 4.0 International license .

A $\mathrm{SMCH}$, Zimbabwe, model 1

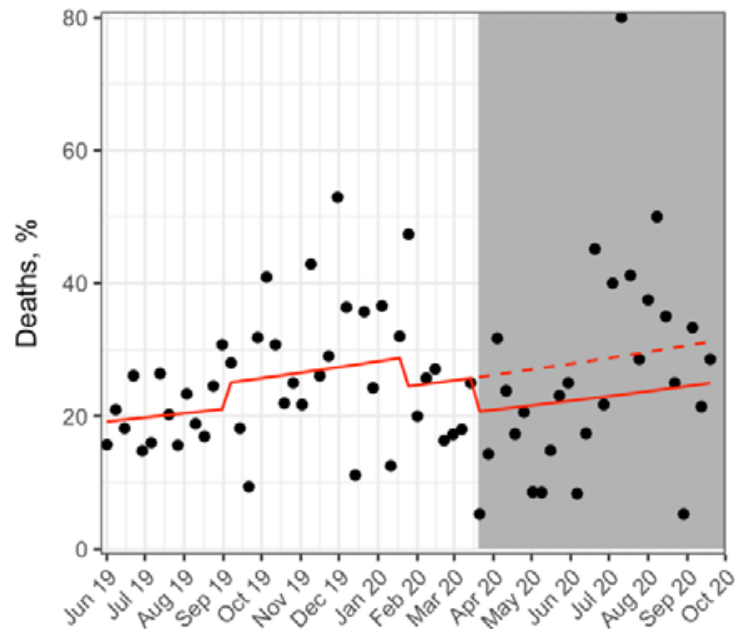

Month

C $\mathrm{KCH}$, Malawi, model 1

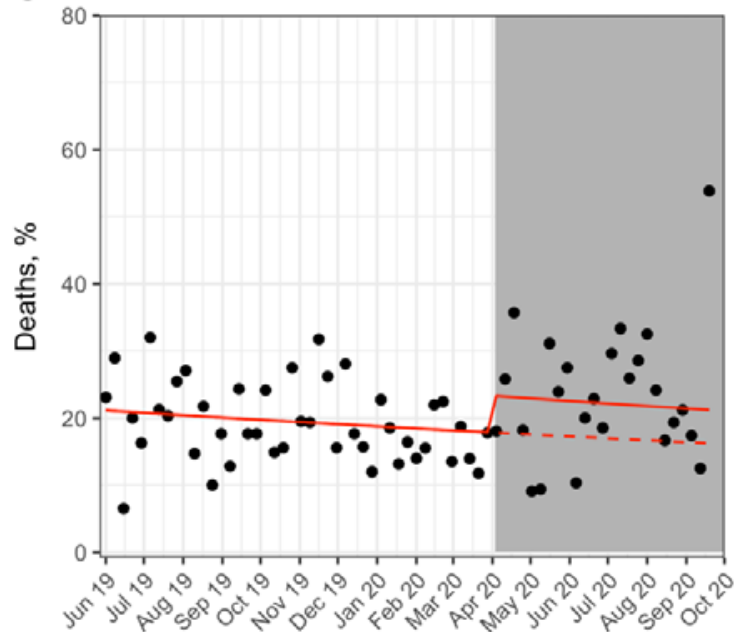

Month
B $\mathrm{SMCH}$, Zimbabwe, model 2

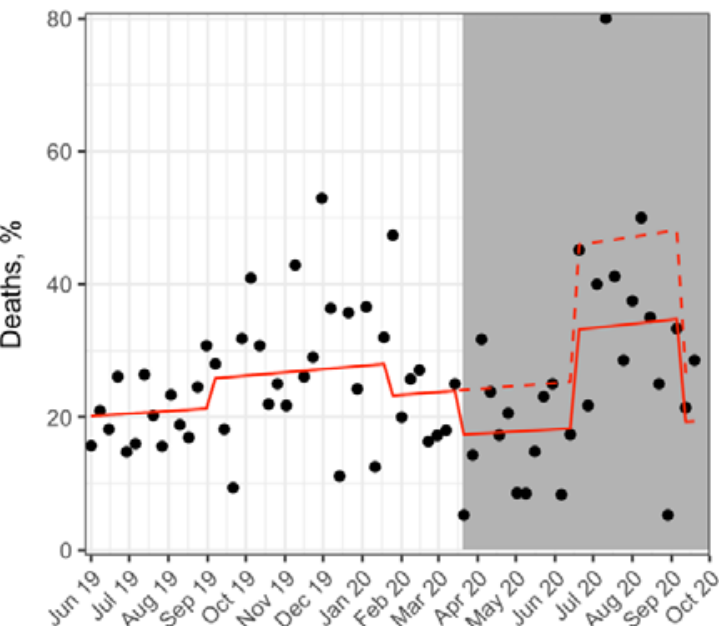

Month

D $\mathrm{KCH}$, Malawi, model 2

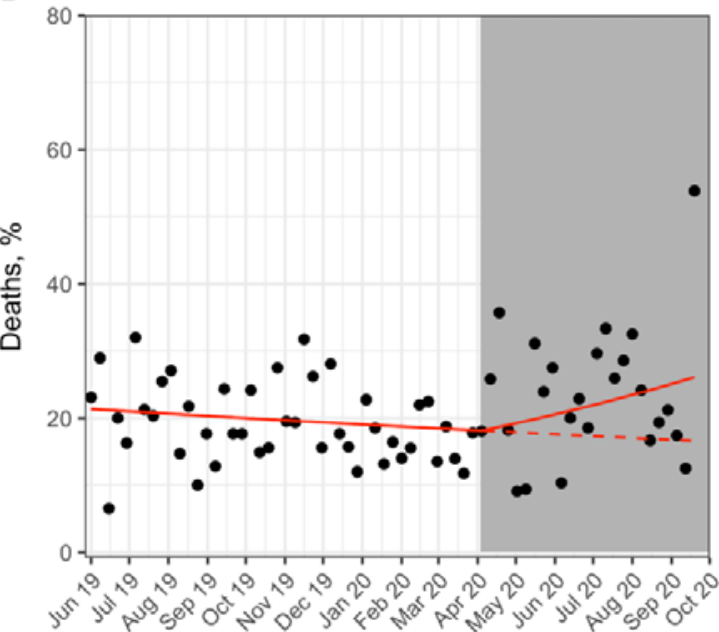

Month

Figure 6: Interrupted time series for overall mortality

- White background: pre-COVID-19 period; grey background: post-COVID-19 period.

- Solid line: predicted trend from regression model; dashed line: counterfactual scenario.

- $\quad \mathrm{SMCH}$ model 1 (panel A) adjusted for doctors' strike period; SMCH model 2 (panel B) additionally adjusted for nurses' strike period; $\mathrm{KCH}$ model 1 (panel $\mathrm{C}$ ) unadjusted level change model; $\mathrm{KCH}$ model 2 (panel D) unadjusted slope change model.

- Data from matched admission and outcome forms only.

- SMCH: Sally Mugabe Central Hospital; KCH: Kamuzu Central Hospital 


\section{DISCUSSION}

\section{Summary}

We performed an interrupted time series analysis to examine changes in neonatal care provision at two tertiary NNUs in Zimbabwe and Malawi after the first cases of COVID-19. We found that admissions at SMCH did not change significantly after the first case of COVID-19 when considering this period as a whole, but there was a considerable decrease ( 50\%) in the number admissions in June to August 2020, coinciding with a nurses' strike. We did not find significant changes in gestational age or birth weight, source of admission referrals, prevalence of NE or mortality at $\mathrm{SMCH}$. Conversely, we found several changes in markers of neonatal care at $\mathrm{KCH}$ after the first case of COVID-19 in Malawi. The number of admissions fell by $42 \%$ and we noted a decrease in the gestational age and birth weight of admitted neonates (by $\sim 1$ week and $\sim 300$ grams, respectively), a 28\% relative decrease in outside referrals, and a small but statistically significant weekly increase in mortality by $2 \%$ after the first case of COVID-19. Although this study is descriptive, we can speculate about explanations for our results based on existing literature and discussions with local health workers.

\section{Interpretation}

The number of admissions at SMCH fell by around $50 \%$ between June to August 2020, but we noted no change outside this strike period, suggesting some resilience to the impact of the pandemic. However, nurses went on strike over pay and availability of personal protective equipment, ${ }^{23}$ so the strike is itself an indirect consequence of COVID-19. A similar reduction in admissions was seen at $\mathrm{KCH}$, but, unlike at $\mathrm{SMCH}$, this $42 \%$ decrease was noted within a week of the first case of 
medRxiv preprint doi: https://doi.org/10.1101/2021.01.06.21249322; this version posted January 6, 2021. The copyright holder for this preprint (which was not certified by peer review) is the author/funder, who has granted medRxiv a license to display the preprint in perpetuity.

It is made available under a CC-BY-NC-ND 4.0 International license .

COVID-19. In Figure 7, we propose several interlinked factors that might explain reduced admissions to the NNU. Several of these factors, such as fear of using health services, disrupted transport networks and staff shortages have been directly reported by local sources in LMICs and were highlighted in a recent report by Graham et al. ${ }^{24}$

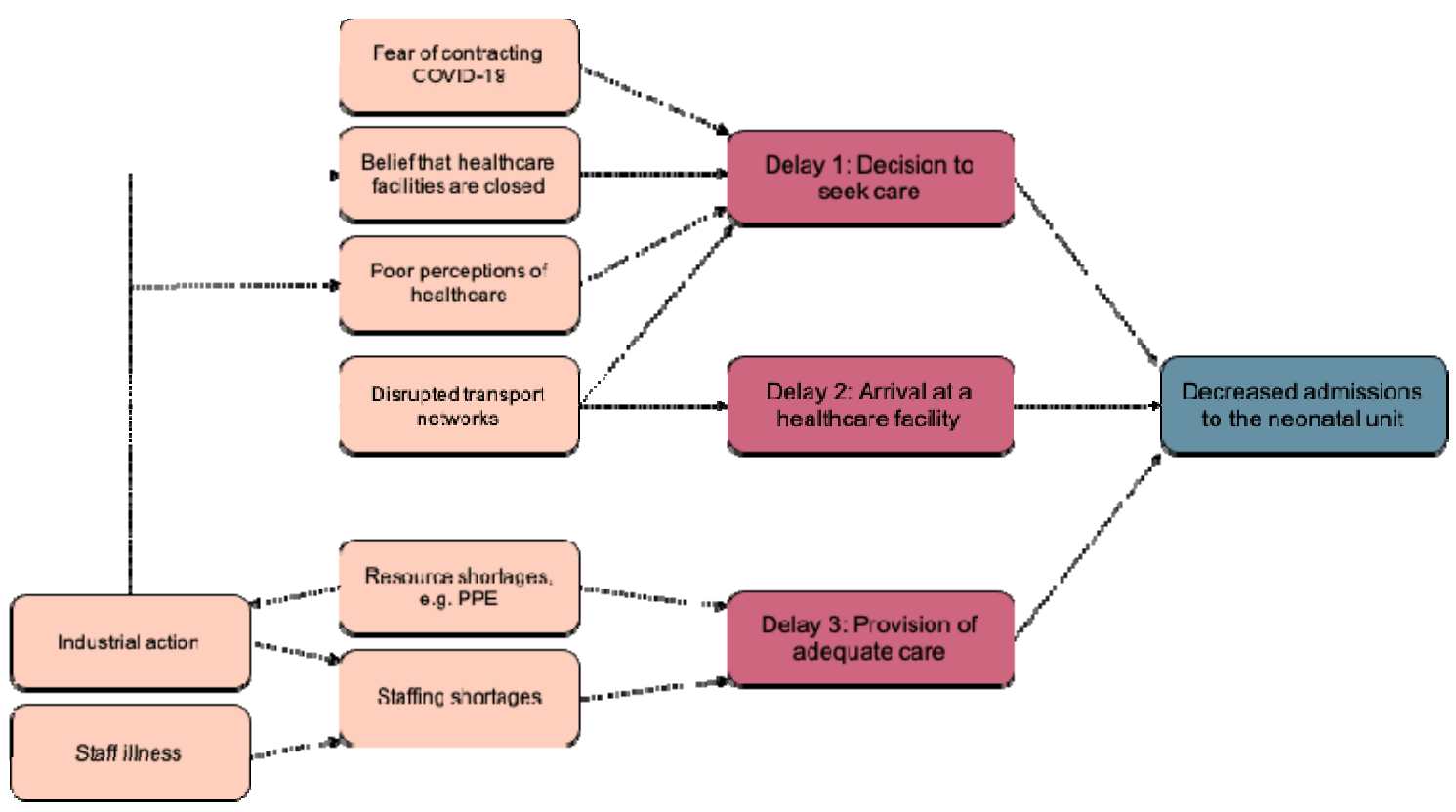

Figure 7: Possible factors influencing the decrease in admissions to the neonatal unit

- Delays (red boxes) derived from the "Three Delays" model of pregnancy-related mortality. ${ }^{25}$

- COVID-19: coronavirus disease 2019; PPE: personal protective equipment

We found a slight decrease in gestational age and birth weight of neonates at $\mathrm{KCH}$, but not SMCH. Studies have reported increased rates of preterm birth in pregnant women with COVID-19 compared to those without the disease, mostly from medically-induced preterm birth; although none of these studies were conducted in LMICs. ${ }^{26}$ Preliminary analysis suggests rates of emergency caesarean section increased at $\mathrm{SMCH}$ and $\mathrm{KCH}$, with a more marked increase at $\mathrm{KCH}$ (Appendix 6). 
This is one potential explanation for our findings. However, we noted that the number of outside referrals decreased by $28 \%$ at $\mathrm{KCH}$, and neonates referred from outside $\mathrm{KCH}$ are more likely to be from lower-risk pregnancies that delivered in a health centre with higher gestational ages and birth weights. Further analysis should stratify by source of admission referral to clarify this finding, but is supported by the fact that referrals were rigorously triaged by the on-call paediatrician during the pandemic, and that referrals from some areas were diverted away from $\mathrm{KCH}$.

We hypothesised that rates of NE would increase during the pandemic. NE is the clinical manifestation of disordered brain function and can have multiple aetiologies. $^{27}$ The term 'hypoxic-ischaemic encephalopathy' is reserved for cases where there is evidence of intrapartum asphyxia. ${ }^{27}$ In LMICs, obstructed labour is a major cause of maternal mortality and can lead to intrapartum asphyxia with subsequent neonatal morbidity and mortality, including NE. ${ }^{28}$ Therefore, the prevalence of NE might be expected to increase as a marker of delayed presentation to a health facility. It is reassuring that we did not find increased rates of NE at $\mathrm{SMCH}$ or $\mathrm{KCH}$. However, these findings should be interpreted cautiously as some neonates with NE may not have presented to a health facility at all.

Finally, we observed a slight increase in overall mortality at $\mathrm{KCH}$ (a relative increase of $2 \%$ per week after the first case of COVID-19), although not at $\mathrm{SMCH}$. In $\mathrm{KCH}$, the increase in mortality may be due to decreased gestational age and birthweight, but also due to a reduced rota of nursing staff implemented to protect healthcare workers. In fact, there was a suggestion that mortality decreased after the first case of COVID-19 in Zimbabwe, but this was not statistically significant. The reasons for 
medRxiv preprint doi: https://doi.org/10.1101/2021.01.06.21249322; this version posted January 6, 2021. The copyright holder for this preprint (which was not certified by peer review) is the author/funder, who has granted medRxiv a license to display the preprint in perpetuity.

It is made available under a CC-BY-NC-ND 4.0 International license .

this are unclear but could include factors such as increased stillbirth rates or improved care for the smaller number of neonates on the NNU. More complete analysis of facility-based and community-based neonatal mortality is greatly needed.

\section{Limitations and future work}

Some limitations should be noted. A limitation intrinsic to interrupted time series analysis is the possibility that another event occurred close to the first case of COVID-19 in either country causing spurious observations. Another potential threat to validity is changing data collection practices. For example, overstretched clinicians might not input data into the NeoTree app for all admitted neonates. However, this is unlikely as the NeoTree app is embedded into routine practice at $\mathrm{SMCH}$ and $\mathrm{KCH}$ and discussions with local collaborators suggest use of the app has continued without issue.

The NeoTree app only collects data on neonates admitted to the NNU. Therefore, our analysis does not capture stillbirths or neonatal deaths that occur in the community. It is troubling to see a dramatic fall in admissions in both sites, raising the possibility that many unwell neonates did not attend a health facility and died at home. A recent study found that facility births decreased by over $50 \%$ during the lockdown in Nepal, and facility stillbirth and neonatal mortality rates increased significantly. ${ }^{29}$ The NeoTree research team is currently collecting data on stillbirths at $\mathrm{SMCH}$ and $\mathrm{KCH}$, but these data will still only represent stillbirths that occurred in a health facility. Given the COVID-19 pandemic is not over, it will be important to repeat our analysis over the coming months to further examine longer-term trends in neonatal care provision. 


\section{Conclusion}

The indirect impacts of COVID-19 are context-specific, with more significant and evident effects on neonatal care provision seen at $\mathrm{KCH}$ (Malawi) than $\mathrm{SMCH}$ (Zimbabwe). While this study provides vital evidence to inform health providers and policy makers, national data are required to ascertain the true impacts of the pandemic on newborn health. 
medRxiv preprint doi: https://doi.org/10.1101/2021.01.06.21249322; this version posted January 6,2021 . The copyright holder for this preprint (which was not certified by peer review) is the author/funder, who has granted medRxiv a license to display the preprint in perpetuity.

It is made available under a CC-BY-NC-ND 4.0 International license .

\section{REFERENCES}

1. World Health Organization. Statement on the second meeting of the International Health Regulations (2005) Emergency Committee regarding the outbreak of novel coronavirus (2019-nCoV). 2020. https://bit.ly/3jihlAU (accessed 04 Sept 2020).

2. World Health Organization. WHO Coronavirus Disease (COVID-19)

Dashboard. 202021 Oct 2020. https://covid19.who.int (accessed 21 Oct 2020).

3. United Nations Inter-agency Group for Child Mortality Estimation. Levels \& Trends in Child Mortality: Report 2019. New York: United Nations Children's Fund, 2019.

4. Makoni M. COVID-19 worsens Zimbabwe's health crisis. Lancet 2020; 396(10249): 457.

5. Truscott R. Covid-19: Health worker strikes, limited testing, and clinic closures hamper Zimbabwe's response. BMJ 2020; 370: m3267.

6. Castagnoli R, Votto M, Licari A, et al. Severe Acute Respiratory Syndrome Coronavirus 2 (SARS-CoV-2) Infection in Children and Adolescents: A Systematic Review. JAMA Pediatr 2020.

7. Götzinger F, Santiago-García B, Noguera-Julián A, et al. COVID-19 in children and adolescents in Europe: a multinational, multicentre cohort study. Lancet Child Adolesc Health 2020; 4(9): 653-61.

8. Ludvigsson JF. Systematic review of COVID-19 in children shows milder cases and a better prognosis than adults. Acta Paediatr 2020; 109(6): 1088-95.

9. Mantovani A, Rinaldi E, Zusi C, Beatrice G, Saccomani MD, Dalbeni A. Coronavirus disease 2019 (COVID-19) in children and/or adolescents: a metaanalysis. Pediatr Res 2020.

10. Viner RM, Mytton OT, Bonell C, et al. Susceptibility to and transmission of COVID-19 amongst children and adolescents compared with adults: a systematic review and meta-analysis. medRxiv 2020: 2020.05.20.20108126.

11. Sochas L, Channon AA, Nam S. Counting indirect crisis-related deaths in the context of a low-resilience health system: the case of maternal and neonatal health during the Ebola epidemic in Sierra Leone. Health Policy Plan 2017; 32(suppl_3): iii32-iii9.

12. Yerger $\mathrm{P}$, Jalloh $\mathrm{M}$, Coltart CEM, King $\mathrm{C}$. Barriers to maternal health services during the Ebola outbreak in three West African countries: a literature review. BMJ Glob Health 2020; 5(9).

13. Ahmed S, Mvalo T, Akech S, et al. Protecting children in low-income and middle-income countries from COVID-19. BMJ Glob Health 2020; 5(5). 
medRxiv preprint doi: https://doi.org/10.1101/2021.01.06.21249322; this version posted January 6, 2021. The copyright holder for this preprint (which was not certified by peer review) is the author/funder, who has granted medRxiv a license to display the preprint in perpetuity.

It is made available under a CC-BY-NC-ND 4.0 International license .

14. Roberton T, Carter ED, Chou VB, et al. Early estimates of the indirect effects of the COVID-19 pandemic on maternal and child mortality in low-income and middle-income countries: a modelling study. Lancet Glob Health 2020; 8(7): e901e8.

15. NeoTree. NeoTree. 2020. https://github.com/neotree/neotree (accessed 03 Oct 2020).

16. Crehan C, Kesler E, Nambiar B, et al. The NeoTree application: developing an integrated $\mathrm{mHealth}$ solution to improve quality of newborn care and survival in a district hospital in Malawi. BMJ Glob Health 2019; 4(1): e000860.

17. Gannon $\mathrm{H}$, Chimhuya S, Chimhini G, et al. An electronic application to improve management of infections in low-income neonatal units: pilot implementation of the NeoTree Beta App in a public sector hospital in Zimbabwe. medRxiv 2020: 2020.09.25.20201467.

18. R Core Team. R: A language and environment for statistical computing. 3.6.3 ed. Vienna, Austria: R Foundation for Statistical Computing; 2020.

19. RStudio Team. RStudio: Integrated Development Environment for R. 1.2.5033 ed. Boston, MA: RStudio, Inc.; 2019.

20. Bernal JL, Cummins S, Gasparrini A. Interrupted time series regression for the evaluation of public health interventions: a tutorial. Int J Epidemiol 2017; 46(1): 348-55.

21. Wedderburn RWM. Quasi-likelihood functions, generalized linear models, and the Gauss-Newton method. Biometrika 1974; 61(3): 439-47.

22. BBC News. Zimbabwe doctors end strike after billionaire's offer. 2020. https://www.bbc.co.uk/news/world-africa-51205619 (accessed 04 Aug 2020).

23. Reuters. Zimbabwe nurses end three-month strike over pay. 2020. https://www.reuters.com/article/us-health-corononavirus-zimbabwe-strikeidUSKBN26011R (accessed 20 Oct 2020).

24. Graham WJ, Afolabi B, Benova L, et al. Protecting hard-won gains for mothers and newborns in low-income and middle-income countries in the face of COVID-19: call for a service safety net. BMJ Glob Health 2020; 5(6).

25. Thaddeus S, Maine D. Too far to walk: maternal mortality in context. Soc Sci Med 1994; 38(8): 1091-110.

26. Khalil A, Kalafat E, Benlioglu C, et al. SARS-CoV-2 infection in pregnancy: A systematic review and meta-analysis of clinical features and pregnancy outcomes. EClinicalMedicine 2020; 25.

27. Robertson NJ, Groenendaal F. Hypoxic-ischaemic brain injury. In: Rennie JM, ed. Rennie and Roberton's Textbook of Neonatology. 5th ed. London: Churchill Livingstone; 2012: 1114-55. 
medRxiv preprint doi: https://doi.org/10.1101/2021.01.06.21249322; this version posted January 6, 2021. The copyright holder for this preprint (which was not certified by peer review) is the author/funder, who has granted medRxiv a license to display the preprint in perpetuity. It is made available under a CC-BY-NC-ND 4.0 International license.

28. Say L, Chou D, Gemmill A, et al. Global causes of maternal death: a WHO systematic analysis. Lancet Glob Health 2014; 2(6): e323-e33.

29. Kc A, Gurung R, Kinney MV, et al. Effect of the COVID-19 pandemic response on intrapartum care, stillbirth, and neonatal mortality outcomes in Nepal: a prospective observational study. Lancet Glob Health 2020; 8(10): e1273-e81. 
medRxiv preprint doi: https://doi.org/10.1101/2021.01.06.21249322; this version posted January 6, 2021. The copyright holder for this preprint (which was not certified by peer review) is the author/funder, who has granted medRxiv a license to display the preprint in perpetuity.

\section{Contributors' statement}

Concept and study design by SC, SRN, GC, FF, MCB, CC, MC and MH with input from other authors. Data collected by HG, DN, TC, CC and THB. Analysis performed by SRN and MCB with contributions from FF, SC, EW \& $\mathrm{MH}$. Manuscript drafted by SC and SRN with input from GC, FF, MCB, MC \& MH. All authors proof-read and approved final draft. Underlying data accessed and verified by SRN, MCB, HG, FF \& $\mathrm{MH}$.

\section{Declaration of interests}

The authors have no conflicts of interest to declare.

\section{Acknowledgements}

We would like to thank the funders of this study. Mr S. R. Neal was awarded the International Child Health Group David Morley Elective Bursary for this elective project. Funders of the wider NeoTree project, past and present, include the Wellcome Trust Digital Innovation Award (215742/Z/19/Z: PI: Heys), RCPCH, Naughton-Cliffe Mathews, UCL Grand Challenges and Global Engagement Fund, and the Healthcare Infection Society (SRG 201802004). Dr F. Fitzgerald is supported by the Academy of Medical Sciences and the funders of the Starter Grants for Clinical Lecturers scheme. This study and Drs M. Heys and F. Fitzgerald are further supported by the National Institute for Health Research Great Ormond Street Hospital Biomedical Research Centre. The funders had no role in study design, data collection and analysis, or preparation of this report. We are very grateful to the families at $\mathrm{SMCH}$ and $\mathrm{KCH}$, and the staff members at both hospitals for their enthusiasm and commitment to the NeoTree project, without which this work would not be possible.

\section{Data sharing statement}

Data collected for the study cannot yet be made publicly available yet because primary analysis for the pilot implementation evaluation of the NeoTree, as well as secondary analysis are ongoing. A goal of our pilot implementation is the establishment of an open-source anonymised research database of data collected using the NeoTree in order to maximise the reach and utility for researchers aiming to improve outcomes for neonates in low income settings. This database is under development and subject to negotiation with relevant Ministries of Health. 


\section{APPENDIX 1: STROBE CHECKLIST}

\begin{tabular}{|c|c|c|c|}
\hline & Item No. & Recommendation & Page No. \\
\hline \multirow[t]{2}{*}{ Title and abstract } & 1 & (a) Indicate the study's design with a commonly used term in the title or the abstract & $1-2$ \\
\hline & & $\begin{array}{l}\text { (b) Provide in the abstract an informative and balanced summary of what was done and what was } \\
\text { found }\end{array}$ & 2 \\
\hline \multicolumn{4}{|c|}{ 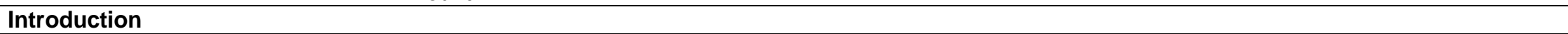 } \\
\hline Background/rationale & 2 & Explain the scientific background and rationale for the investigation being reported & $6-7$ \\
\hline Objectives & 3 & State specific objectives, including any prespecified hypotheses & 7 \\
\hline \multicolumn{4}{|l|}{ Methods } \\
\hline Study design & 4 & Present key elements of study design early in the paper & $7-8$ \\
\hline Setting & 5 & $\begin{array}{l}\text { Describe the setting, locations, and relevant dates, including periods of recruitment, exposure, } \\
\text { follow-up, and data collection }\end{array}$ & 8 \\
\hline \multirow[t]{3}{*}{ Participants } & 6 & $\begin{array}{l}\text { (a) Cohort study-Give the eligibility criteria, and the sources and methods of selection of } \\
\text { participants. Describe methods of follow-up } \\
\text { Case-control study-Give the eligibility criteria, and the sources and methods of case } \\
\text { ascertainment and control selection. Give the rationale for the choice of cases and controls } \\
\text { Cross-sectional study-Give the eligibility criteria, and the sources and methods of selection of } \\
\text { participants }\end{array}$ & 8 \\
\hline & & $\begin{array}{l}\text { (b) Cohort study-For matched studies, give matching criteria and number of exposed and } \\
\text { unexposed }\end{array}$ & \\
\hline & & $\begin{array}{l}\text { Case-control study_For matched studies, give matching criteria and the number of controls per } \\
\text { case }\end{array}$ & \\
\hline Variables & 7 & $\begin{array}{l}\text { Clearly define all outcomes, exposures, predictors, potential confounders, and effect modifiers. } \\
\text { Give diagnostic criteria, if applicable }\end{array}$ & 9 \\
\hline $\begin{array}{l}\text { Data sources/ } \\
\text { measurement }\end{array}$ & $8^{*}$ & $\begin{array}{l}\text { For each variable of interest, give sources of data and details of methods of assessment } \\
\text { (measurement). Describe comparability of assessment methods if there is more than one group }\end{array}$ & 9 \\
\hline Bias & 9 & Describe any efforts to address potential sources of bias & $9-10$ \\
\hline Study size & 10 & Explain how the study size was arrived at & 10 \\
\hline Quantitative variables & 11 & $\begin{array}{l}\text { Explain how quantitative variables were handled in the analyses. If applicable, describe which } \\
\text { groupings were chosen and why }\end{array}$ & $9-10$ \\
\hline \multirow[t]{4}{*}{ Statistical methods } & 12 & (a) Describe all statistical methods, including those used to control for confounding & $10-11$ \\
\hline & & (b) Describe any methods used to examine subgroups and interactions & $10-11$ \\
\hline & & (c) Explain how missing data were addressed & $10-11,34$ \\
\hline & & $\begin{array}{l}\text { (d) Cohort study_If applicable, explain how loss to follow-up was addressed } \\
\text { Case-control study_-If applicable, explain how matching of cases and controls was addressed } \\
\text { Cross-sectional study_-If applicable, describe analytical methods taking account of sampling }\end{array}$ & $10-11$ \\
\hline
\end{tabular}




\begin{tabular}{|c|c|c|c|}
\hline & & \multicolumn{2}{|l|}{ strategy } \\
\hline & & (e) Describe any sensitivity analyses & 10-11, 33-44 \\
\hline \multicolumn{4}{|l|}{ Results } \\
\hline \multirow[t]{3}{*}{ Participants } & $13^{*}$ & $\begin{array}{l}\text { (a) Report numbers of individuals at each stage of study-eg numbers potentially eligible, } \\
\text { examined for eligibility, confirmed eligible, included in the study, completing follow-up, and } \\
\text { analysed }\end{array}$ & 12-14, 33 \\
\hline & & (b) Give reasons for non-participation at each stage & $12-14$ \\
\hline & & (c) Consider use of a flow diagram & 33 \\
\hline \multirow[t]{3}{*}{ Descriptive data } & $14^{*}$ & $\begin{array}{l}\text { (a) Give characteristics of study participants (eg demographic, clinical, social) and information on } \\
\text { exposures and potential confounders }\end{array}$ & $12-16,35-42$ \\
\hline & & (b) Indicate number of participants with missing data for each variable of interest & 33-34 \\
\hline & & (c) Cohort study-Summarise follow-up time (eg, average and total amount) & $12-20$ \\
\hline \multirow[t]{3}{*}{ Outcome data } & $15^{*}$ & Cohort study-Report numbers of outcome events or summary measures over time & $12-20$ \\
\hline & & $\begin{array}{l}\text { Case-control study-Report numbers in each exposure category, or summary measures of } \\
\text { exposure }\end{array}$ & \\
\hline & & Cross-sectional study-Report numbers of outcome events or summary measures & \\
\hline \multirow[t]{3}{*}{ Main results } & 16 & $\begin{array}{l}\text { (a) Give unadjusted estimates and, if applicable, confounder-adjusted estimates and their } \\
\text { precision (eg, } 95 \% \text { confidence interval). Make clear which confounders were adjusted for and why } \\
\text { they were included }\end{array}$ & $12-20$ \\
\hline & & (b) Report category boundaries when continuous variables were categorized & $12-20$ \\
\hline & & $\begin{array}{l}\text { (c) If relevant, consider translating estimates of relative risk into absolute risk for a meaningful time } \\
\text { period }\end{array}$ & $12-20$ \\
\hline Other analyses & 17 & Report other analyses done-eg analyses of subgroups and interactions, and sensitivity analyses & $34-42$ \\
\hline \multicolumn{4}{|c|}{ (1) } \\
\hline Key results & 18 & Summarise key results with reference to study objectives & 21 \\
\hline Limitations & 19 & $\begin{array}{l}\text { Discuss limitations of the study, taking into account sources of potential bias or imprecision. } \\
\text { Discuss both direction and magnitude of any potential bias }\end{array}$ & 24 \\
\hline Interpretation & 20 & $\begin{array}{l}\text { Give a cautious overall interpretation of results considering objectives, limitations, multiplicity of } \\
\text { analyses, results from similar studies, and other relevant evidence }\end{array}$ & $21-24$ \\
\hline Generalisability & 21 & Discuss the generalisability (external validity) of the study results & $22-24$ \\
\hline \multicolumn{4}{|c|}{ Other information } \\
\hline Funding & 22 & $\begin{array}{l}\text { Give the source of funding and the role of the funders for the present study and, if applicable, for } \\
\text { the original study on which the present article is based }\end{array}$ & 29 \\
\hline
\end{tabular}




\section{APPENDIX 2: ETHICAL APPROVAL}

Ethical approval for this study was granted by the following ethics committees.

\section{Committee}

United Kingdom

University College London Research Ethics Committee

Malawi

College of Medicine Research and Ethics Committee

Zimbabwe

Medical Research Council of Zimbabwe

Joint Research Ethics Committee for the University of Zimbabwe,

College of Health Sciences and Parirenyatwa Group of Hospitals

Biomedical Research and Training Institute Institutional Review Board

Sally Mugabe (Harare) Central Hospital Ethics Committee

\section{Reference}

$17123 / 001$

P.01/20/2909

$\mathrm{MRCZ/A} / 2570$

JREC/327/19

AP155/2020

$071119 / 64$ 


\section{APPENDIX 3: FLOW DIAGRAMS OF RECORD INCLUSION}

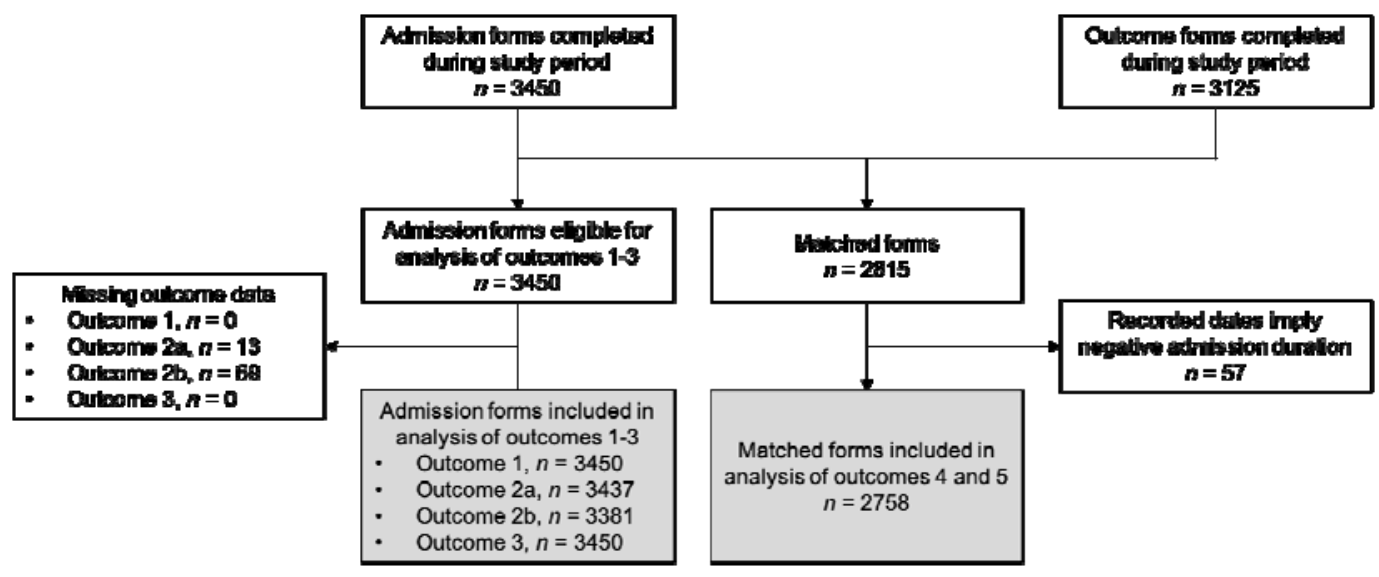

Flow diagram of record inclusion for analysis of data at Sally Mugabe Central Hospital,

\section{Zimbabwe}

- Outcome 1: number of admissions

- Outcome 2a: gestational age

- Outcome 2b: birth weight

- Outcome 3: source of admission

- Outcome 4: prevalence of neonatal encephalopathy

- Outcome 5: overall mortality rate

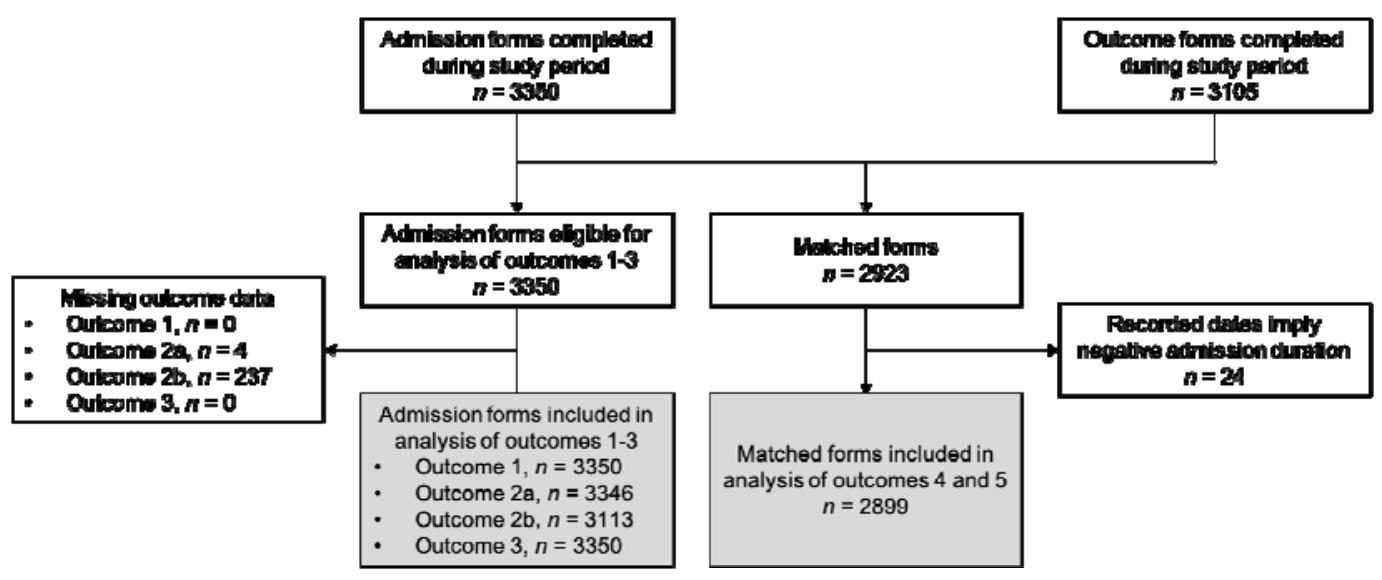

Flow diagram of record inclusion for analysis of data at Kamuzu Central Hospital, Malawi

- Outcome 1: number of admissions

- Outcome 2a: gestational age

- Outcome 2b: birth weight

- Outcome 3: source of admission

- Outcome 4: prevalence of neonatal encephalopathy

- Outcome 5: overall mortality rate 


\section{APPENDIX 4: MISSING DATA}

The table below shows the number of participants with missing data for each outcome and the number of participants remaining for each analysis after pairwise deletion of missing values.

\begin{tabular}{lllll}
\hline \multirow{2}{*}{ Characteristics } & \multicolumn{3}{c}{$n$ missing (\%) } & \multicolumn{2}{c}{$n$ remaining $^{*}$} \\
\cline { 2 - 5 } & SMCH & KCH & SMCH & KCH \\
\hline Gestational age & $13(0 \cdot 4)$ & $4(0 \cdot 1)$ & $3437(99 \cdot 6)$ & $3346(99 \cdot 9)$ \\
Birth weight & $69(2 \cdot 0)$ & $237(7 \cdot 1)$ & $3381(98 \cdot 0)$ & $3113(92 \cdot 9)$ \\
Source of admission & $0(0.0)$ & $0(0 \cdot 0)$ & $3450(100 \cdot 0)$ & $3350(100 \cdot 0)$ \\
Neonatal encephalopathy & $0(0 \cdot 0)$ & $0(0.0)$ & $2758(100 \cdot 0) \dagger$ & $2899(100 \cdot 0) \dagger$ \\
Death & $0(0 \cdot 0)$ & $0(0.0)$ & $2758(100 \cdot 0) \dagger$ & $2899(100 \cdot 0) \dagger$ \\
\hline
\end{tabular}

- $\quad$ * Remaining for analysis after pairwise deletion.

- † Only matched admission and outcome forms considered for analysis of neonatal encephalopathy and death.

- SMCH: Sally Mugabe Central Hospital; KCH: Kamuzu Central Hospital, Malawi 


\section{APPENDIX 5: FURTHER REGRESSION ANALYSIS RESULTS}

\section{Outcome 1: Admissions to the neonatal unit}
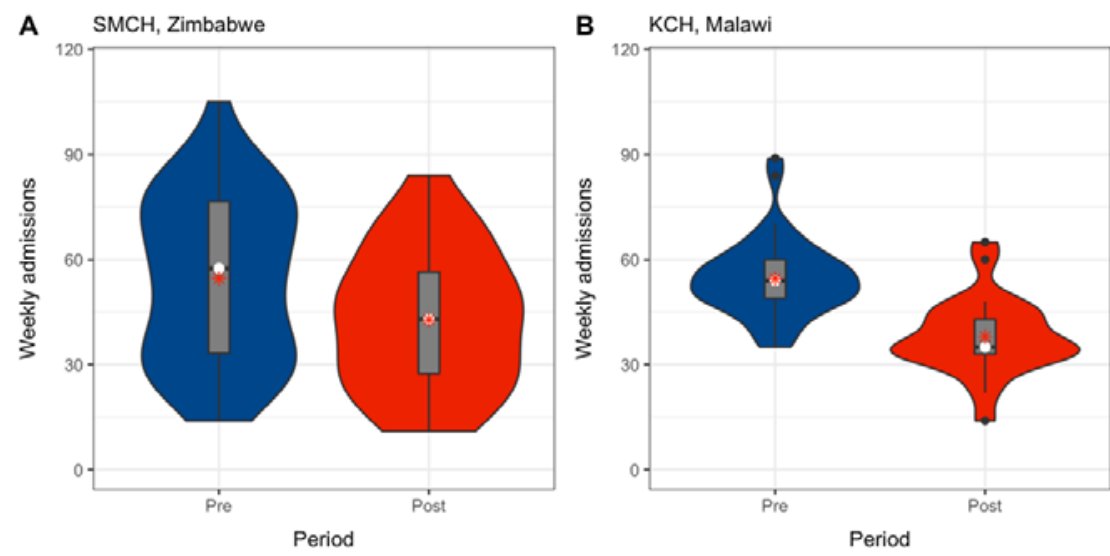

Distribution of weekly admissions by COVID-19 period

SMCH model 1: Level change model, adjusted for doctors' strike period

\begin{tabular}{|l|c|c|c|c|c|}
\hline & Coef & SE & Exp & $95 \%$ Cl & $p$-value \\
\hline Intercept & 4.43 & 0.08 & 84.31 & $71.89-98.86$ & $<0.001$ \\
\hline Post-COVID-19 period, yes & -0.19 & 0.17 & 0.83 & $0.60-1.14$ & 0.25 \\
\hline Study time elapsed, weeks & -0.009 & 0.004 & 0.99 & $0.98-1.00$ & 0.012 \\
\hline Doctors' strike period, yes & -0.68 & 0.11 & 0.51 & $0.41-0.63$ & $<0.001$ \\
\hline
\end{tabular}

SMCH model 2: Level change model, additionally adjusted for nurses' strike period

\begin{tabular}{|l|c|c|c|c|c|}
\hline & Coef & SE & Exp & $95 \% \mathbf{C l}$ & $\boldsymbol{p}$-value \\
\hline Intercept & 4.37 & 0.07 & 79.20 & $68.81-91.16$ & $<0.001$ \\
\hline Post- COVID-19 period, yes & -0.11 & 0.14 & 0.90 & $0.69-1.17$ & 0.90 \\
\hline Study time elapsed, weeks & -0.005 & 0.003 & 1.00 & $0.99-1.00$ & 0.10 \\
\hline Doctors' strike period, yes & -0.70 & 0.09 & 0.50 & $0.41-0.60$ & $<0.001$ \\
\hline Nurses' strike period, yes & -0.65 & 0.14 & 0.52 & $0.40-0.68$ & $<0.001$ \\
\hline
\end{tabular}

KCH model: Level change model, unadjusted

\begin{tabular}{|l|c|c|c|c|c|}
\hline & Coef & SE & Exp & 95\% Cl & $p$-value \\
\hline Intercept & 3.88 & 0.06 & 48.42 & $43.03-54.49$ & $<0.001$ \\
\hline Post- COVID-19 period, yes & -0.55 & 0.10 & 0.58 & $0.48-0.70$ & $<0.001$ \\
\hline Study time elapsed, weeks & 0.005 & 0.002 & 1.01 & $1.00-1.01$ & 0.019 \\
\hline
\end{tabular}




\title{
Outcome 2: Gestational age at birth and birth weight
}

\author{
Gestational age at birth
}
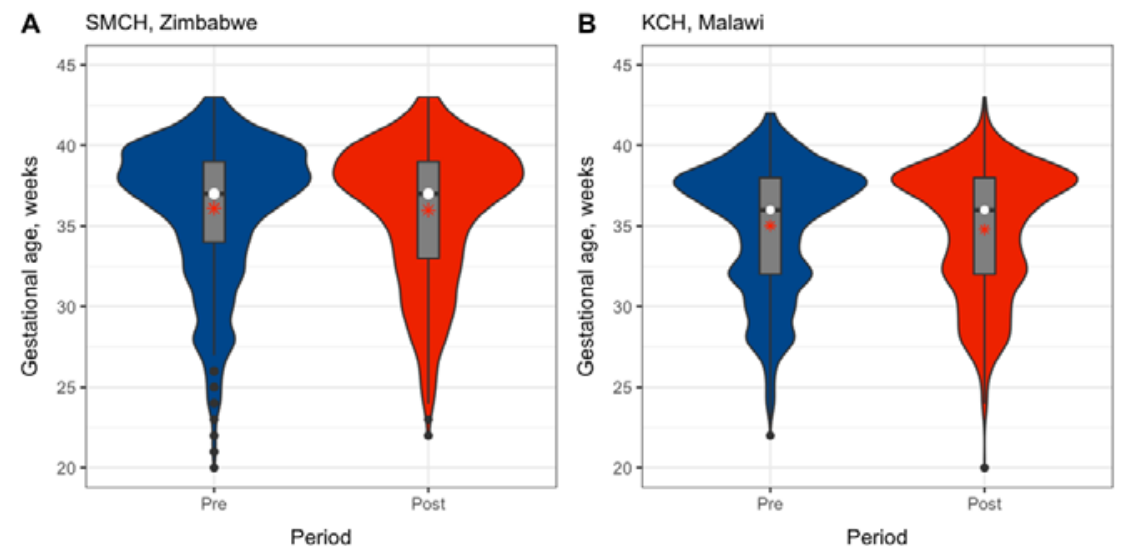

Distribution of gestational age at birth (weeks) by COVID-19 (pre/post-COVID19) period

SMCH model: Level change model, adjusted for doctors' strike period

\begin{tabular}{|l|c|c|c|c|}
\hline & Coef & SE & $\mathbf{9 5 \%}$ Cl & $\boldsymbol{p}$-value \\
\hline Intercept & 36.25 & 0.15 & $35.96-36.54$ & $<0.001$ \\
\hline Post-COVID-19 period, yes & 0.04 & 0.29 & $-0.53-0.61$ & 0.89 \\
\hline Study time elapsed, weeks & -0.006 & 0.006 & $-0.02-0.007$ & 0.37 \\
\hline Doctors' strike period, yes & -0.17 & 0.20 & $-0.57-0.23$ & 0.41 \\
\hline
\end{tabular}

$\mathrm{KCH}$ model: Level change model, unadjusted

\begin{tabular}{|l|c|c|c|c|}
\hline & Coef & SE & $\mathbf{9 5 \% ~ C l}$ & $\boldsymbol{p}$-value \\
\hline Intercept & 34.42 & 0.15 & $34.12-34.72$ & $<0.001$ \\
\hline Post-COVID-19 period, yes & -1.14 & 0.25 & $-1.62--0.65$ & $<0.001$ \\
\hline Study time elapsed, weeks & 0.03 & 0.006 & $0.02-0.04$ & $<0.001$ \\
\hline
\end{tabular}


medRxiv preprint doi: https://doi.org/10.1101/2021.01.06.21249322; this version posted January 6,2021 . The copyright holder for this preprint (which was not certified by peer review) is the author/funder, who has granted medRxiv a license to display the preprint in perpetuity.

It is made available under a CC-BY-NC-ND 4.0 International license.

\section{Birth weight}
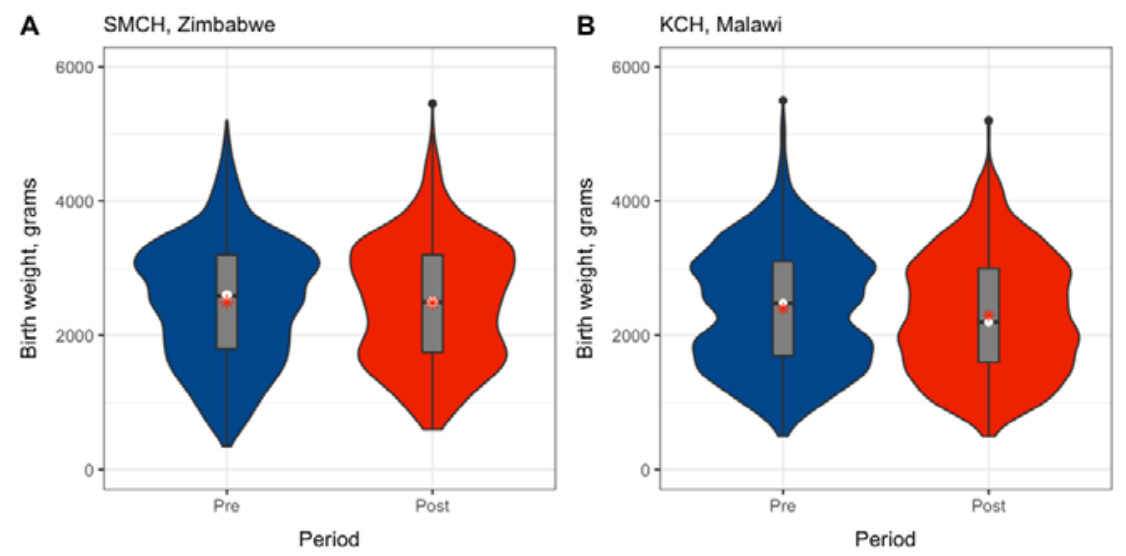

Distribution of birth weight (grams) by COVID-19 (pre/post-COVID19) period

SMCH model: Level change model, adjusted for doctors' strike period

\begin{tabular}{|l|c|c|c|c|}
\hline & Coef & SE & 95\% Cl & $\boldsymbol{p}$-value \\
\hline Intercept & $2530 \cdot 0$ & 31.5 & $2468.0-2591.4$ & $<0.001$ \\
\hline Post- COVID-19 period, yes & $-7 \cdot 2$ & 61.1 & $-127 \cdot 1-112.6$ & 0.91 \\
\hline Study time elapsed, weeks & -0.7 & 1.3 & $-3.3-2.0$ & 0.62 \\
\hline Doctors' strike period, yes & -58.1 & 42.9 & $-142 \cdot 1-25.9$ & 0.18 \\
\hline
\end{tabular}

KCH model: Level change model, unadjusted

\begin{tabular}{|l|c|c|c|c|}
\hline & Coef & SE & $\mathbf{9 5 \%} \mathbf{C l}$ & $\boldsymbol{p}$-value \\
\hline Intercept & $2269 \cdot 0$ & 36.0 & $2198.4-2339 \cdot 6$ & $<0.001$ \\
\hline Post- COVID-19 period, yes & -299.9 & 57.3 & $-412.3--187.5$ & $<0.001$ \\
\hline Study time elapsed, weeks & 5.9 & 1.4 & $3.2-8.6$ & $<0.001$ \\
\hline
\end{tabular}




\section{Outcome 3: Source of admission referral}

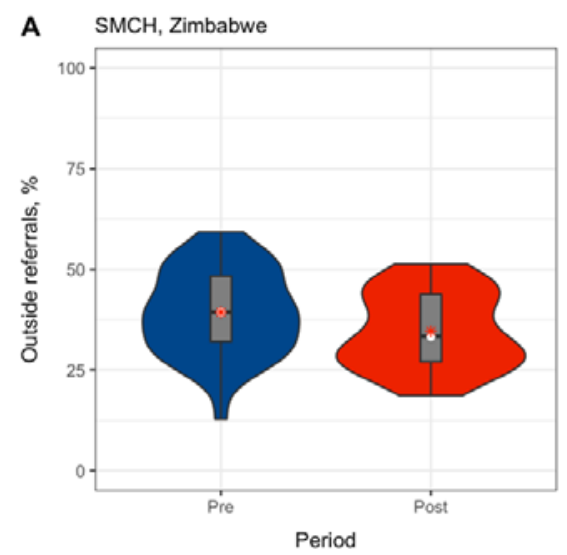

Distribution of outside referrals

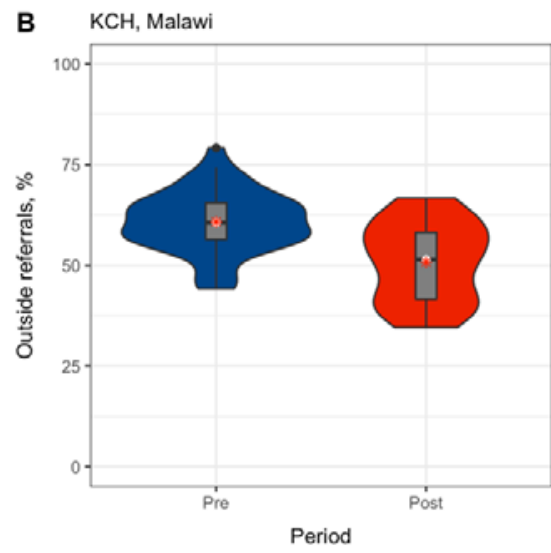

(\%) by pre/post-COVID-19 period

SMCH model: Level change model, adjusted for doctors' strike period

\begin{tabular}{|l|c|c|c|c|c|}
\hline & Coef & SE & Exp & $95 \%$ Cl & $p$-value \\
\hline Intercept & -1.15 & 0.06 & 0.32 & $0.28-0.36$ & $<0.001$ \\
\hline Post- COVID-19 period, yes & -0.02 & 0.11 & 0.98 & $0.79-1.23$ & 0.88 \\
\hline Study time elapsed, weeks & 0.001 & 0.003 & 1.00 & $1.00-1.01$ & 0.55 \\
\hline Doctors' strike period, yes & 0.33 & 0.07 & 1.39 & $1.20-1.60$ & $<0.001$ \\
\hline
\end{tabular}

KCH model: Level change model, unadjusted

\begin{tabular}{|l|c|c|c|c|c|}
\hline & Coef & SE & Exp & $\mathbf{9 5 \%}$ Cl & $\boldsymbol{p}$-value \\
\hline Intercept & -0.59 & 0.04 & 0.55 & $0.51-0.59$ & $<0.001$ \\
\hline Post- COVID-19 period, yes & -0.33 & 0.06 & 0.72 & $0.65-0.81$ & $<0.001$ \\
\hline Study time elapsed, weeks & 0.005 & 0.001 & 1.01 & $1.00-1.01$ & 0.001 \\
\hline
\end{tabular}




\section{Outcome 4: Prevalence of neonatal encephalopathy}
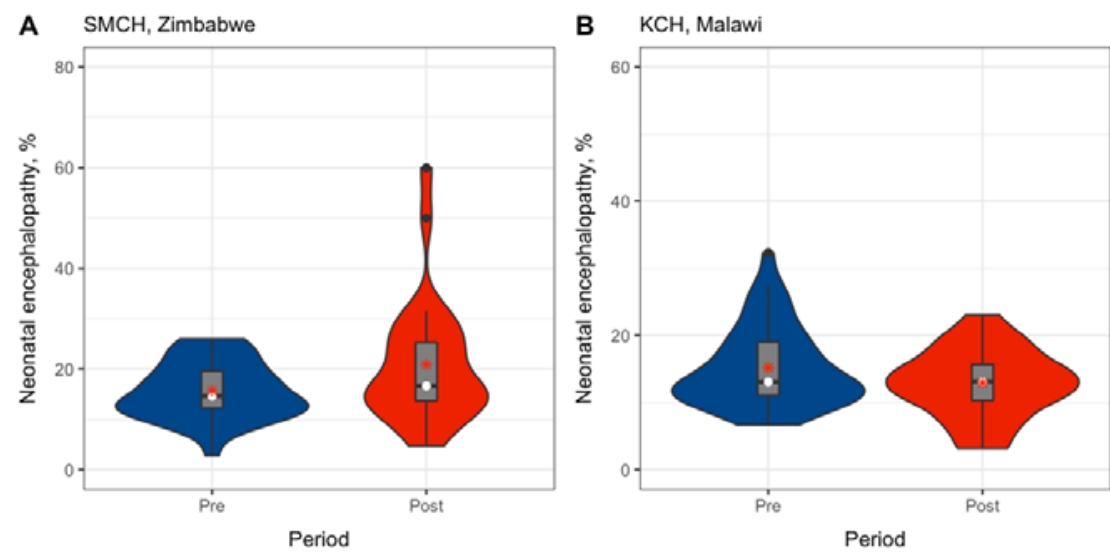

Distribution of neonatal encephalopathy (\%) by pre/post-COVID-19 period

SMCH model: Level change model, adjusted for doctors' strike period

\begin{tabular}{|l|c|c|c|c|c|}
\hline & Coef & SE & Exp & $\mathbf{9 5 \%}$ Cl & $\boldsymbol{p}$-value \\
\hline Intercept & -1.93 & 0.10 & 0.15 & $0.12-0.18$ & $<0.001$ \\
\hline Post- COVID-19 period, yes & 0.08 & 0.18 & 1.08 & $0.76-1.55$ & 0.67 \\
\hline Study time elapsed, weeks & 0.004 & 0.004 & 1.00 & $1.00-1.01$ & 0.27 \\
\hline Doctors' strike period, yes & -0.02 & 0.13 & 0.98 & $0.76-1.26$ & 0.87 \\
\hline
\end{tabular}

$\mathrm{KCH}$ model: Level change model, unadjusted

\begin{tabular}{|l|c|c|c|c|c|}
\hline & Coef & SE & Exp & $95 \%$ Cl & $p$-value \\
\hline Intercept & -1.66 & 0.09 & 0.19 & $0.16-0.23$ & $<0.001$ \\
\hline Post- COVID-19 period, yes & 0.27 & 0.16 & 1.30 & $0.95-1.80$ & 0.11 \\
\hline Study time elapsed, weeks & -0.01 & 0.004 & 0.99 & $0.98-1.00$ & 0.001 \\
\hline
\end{tabular}




\section{Outcome 5: Overall mortality}
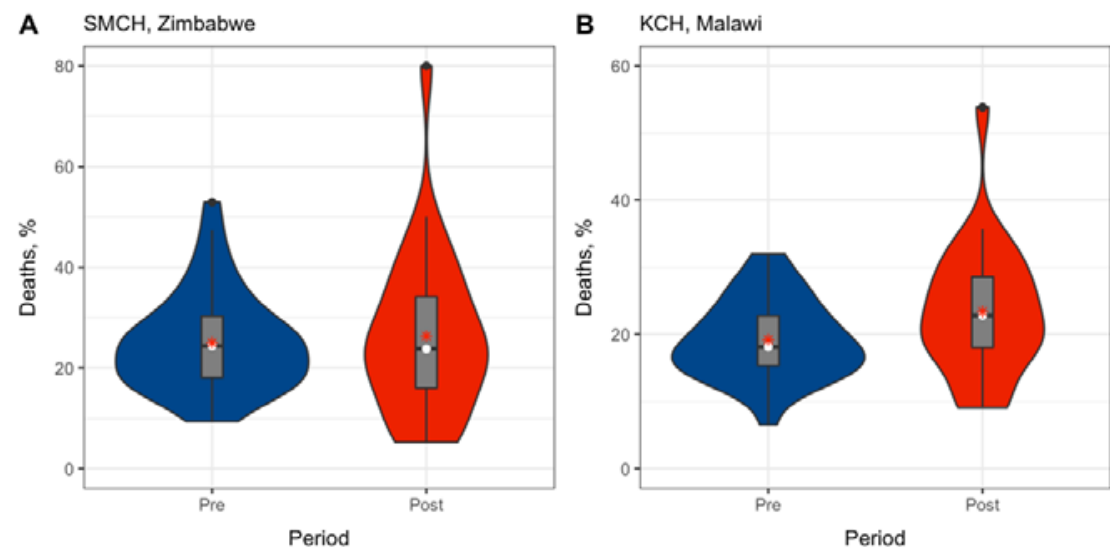

Distribution of overall mortality (\%) by pre/post-COVID-19 period

SMCH model 1: Level change model, adjusted for doctors' strike period

\begin{tabular}{|l|c|c|c|c|c|}
\hline & Coef & SE & Exp & $\mathbf{9 5 \%}$ Cl & $\boldsymbol{p}$-value \\
\hline Intercept & -1.65 & 0.08 & 0.19 & $0.16-0.23$ & $<0.001$ \\
\hline Post- COVID-19 period, yes & -0.22 & 0.16 & 0.80 & $0.56-1.15$ & 0.23 \\
\hline Study time elapsed, weeks & 0.007 & 0.003 & 1.01 & $1.00-1.02$ & 0.09 \\
\hline Doctors' strike period, yes & 0.17 & 0.10 & 1.19 & $0.94-1.50$ & 0.16 \\
\hline
\end{tabular}

SMCH model 2: Level change model, additionally adjusted for nurses' strike period

\begin{tabular}{|l|c|c|c|c|c|}
\hline & Coef & SE & Exp & $\mathbf{9 5 \%} \mathbf{C l}$ & $\boldsymbol{p}$-value \\
\hline Intercept & -1.60 & 0.09 & 0.20 & $0.17-0.24$ & $<0.001$ \\
\hline Post- COVID-19 period, yes & -0.33 & 0.18 & 0.72 & $0.51-1.03$ & 0.07 \\
\hline Study time elapsed, weeks & 0.004 & 0.004 & 1.00 & $1.00-1.01$ & 0.30 \\
\hline Doctors' strike period, yes & 0.19 & 0.11 & 1.21 & $0.98-1.50$ & 0.08 \\
\hline Nurses' strike period, yes & 0.60 & 0.17 & 1.82 & $1.30-2.55$ & 0.001 \\
\hline
\end{tabular}

KCH model 1: Level change model, unadjusted

\begin{tabular}{|l|c|c|c|c|c|}
\hline Mal - deaths (unadjusted) & Coef & \multicolumn{1}{l|}{ SE } & Exp & $\mathbf{9 5 \%} \mathbf{C l}$ & $\boldsymbol{p}$-value \\
\hline Intercept & -1.56 & 0.09 & 0.21 & $0.18-0.25$ & $<0.001$ \\
\hline Post- COVID-19 period, yes & 0.27 & 0.14 & 1.31 & $0.98-1.73$ & 0.07 \\
\hline Study time elapsed, weeks & -0.004 & 0.003 & 1.00 & $0.99-1.00$ & 0.27 \\
\hline
\end{tabular}


medRxiv preprint doi: https://doi.org/10.1101/2021.01.06.21249322; this version posted January 6,2021 . The copyright holder for this preprint (which was not certified by peer review) is the author/funder, who has granted medRxiv a license to display the preprint in perpetuity. It is made available under a CC-BY-NC-ND 4.0 International license.

KCH model 2: Slope change model, unadjusted

\begin{tabular}{|l|c|c|c|c|c|}
\hline Mal - deaths (sensitivity) & Coef & SE & Exp & $\mathbf{9 5 \%}$ Cl & $\boldsymbol{p}$-value \\
\hline Intercept & -1.55 & 0.09 & 0.21 & $0.18-0.25$ & $<0.001$ \\
\hline Study time elapsed, weeks & -0.004 & 0.003 & 1.00 & $0.99-1.00$ & 0.25 \\
\hline $\begin{array}{l}\text { Time since first COVID-19 case, } \\
\text { weeks * post- COVID-19 period, } \\
\text { yes }\end{array}$ & 0.02 & 0.009 & 1.02 & $1.00-1.04$ & 0.04 \\
\hline
\end{tabular}




\section{APPENDIX 6: ADDITIONAL ANALYSES}

\section{Mode of delivery of admitted neonates}

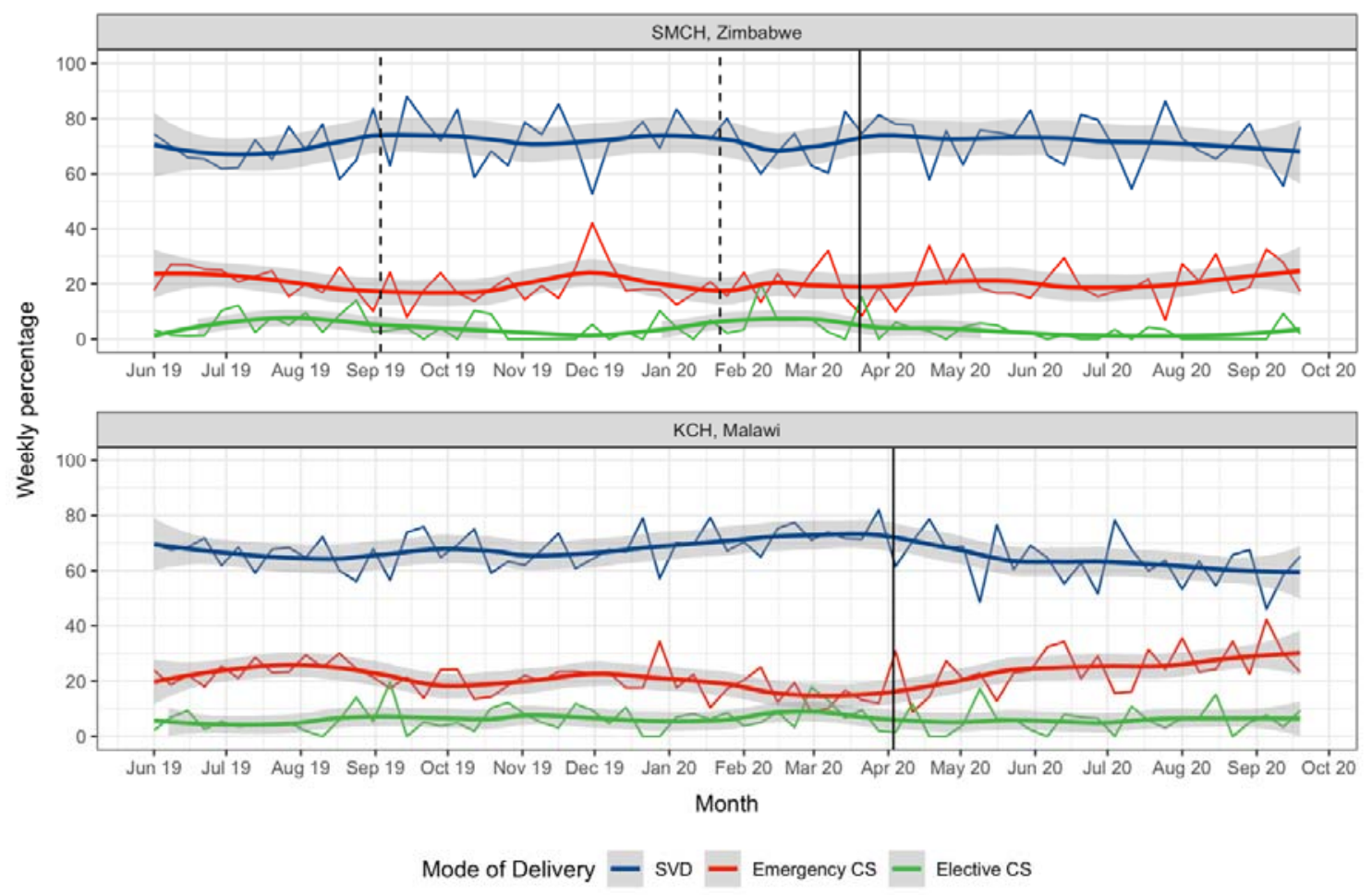

Trend in mode of delivery of admitted neonates per week

- Only SVD, emergency CS and elective CS displayed here to avoid overplotting.

- Smoothed line: local regression (LOESS) model; shaded region: 95\% confidence interval.

- Solid vertical line: first confirmed case of COVID-19 in each country.

- Period between dashed vertical lines: industrial action by doctors in Zimbabwe.

- Counts based on all admission forms completed, irrespective of match status.

- SMCH: Sally Mugabe Central Hospital; KCH: Kamuzu Central Hospital; SVD: spontaneous vaginal delivery; CS: caesarean section 